\title{
A FORWARD LOOKING RICARDIAN APPROACH: DO LAND MARKETS CAPITALIZE CLIMATE CHANGE FORECASTS?
}

\author{
Christopher Severen \\ Christopher Costello \\ Olivier Deschenes \\ Working Paper 22413 \\ http://www.nber.org/papers/w22413 \\ NATIONAL BUREAU OF ECONOMIC RESEARCH \\ 1050 Massachusetts Avenue \\ Cambridge, MA 02138 \\ July 2016
}

This project has received insightful comments and feedback from Joshua Abbott, Bowman Cutter, Peter Kuhn, Kyle Meng, Matto Mildenberger, Steve Miller, Kevin Roth, Richard Startz, and Christopher Timmons, as well as the UCSB Econometrics Research Group and the Bren Economics Lab. The views expressed herein are those of the authors and do not necessarily reflect the views of the National Bureau of Economic Research.

NBER working papers are circulated for discussion and comment purposes. They have not been peer-reviewed or been subject to the review by the NBER Board of Directors that accompanies official NBER publications.

(C) 2016 by Christopher Severen, Christopher Costello, and Olivier Deschenes. All rights reserved. Short sections of text, not to exceed two paragraphs, may be quoted without explicit permission provided that full credit, including $\odot$ notice, is given to the source. 
A Forward Looking Ricardian Approach: Do Land Markets Capitalize Climate Change Forecasts? Christopher Severen, Christopher Costello, and Olivier Deschenes

NBER Working Paper No. 22413

July 2016

JEL No. Q12,Q50,Q51,Q54

\begin{abstract}
$\underline{\text { ABSTRACT }}$
The hedonic pricing method is one of the fundamental approaches used to estimate the economic value of attributes that affect the market price of an asset. In environmental economics, such methods are routinely used to derive the economic valuation of environmental attributes such as air pollution and water quality. For example, the Ricardian approach is based on a hedonic regression of land values on historical climate variables. Forecasts of future climate can then be employed to estimate the future costs of climate change. This extensively-applied approach contains an important implicit assumption that current land markets ignore current climate forecasts. While this assumption was defensible decades ago (when this literature first emerged), it is reasonable to hypothesize that information on climate change is so pervasive today that markets may already price in expectations of future climate change. We show how to account for this with a straightforward empirical correction (called the Forward-Looking Ricardian Approach) that can be implemented with readily available data. We apply this empirically to agricultural land markets in the United States and find evidence that these markets already are accounting for climate change forecasts. Failing to account for this would lead a researcher to understate climate change damages by $36 \%$ to $66 \%$.
\end{abstract}

Christopher Severen

University of California at Santa Barbara

Department of Economics

cseveren@umail.ucsb.edu

Christopher Costello

Bren School of Environmental

Science \& Management

University of California, Santa Barbara

Santa Barbara, CA 93106

and NBER

costello@bren.ucsb.edu
Olivier Deschenes

Department of Economics

2127 North Hall

University of California, Santa Barbara

Santa Barbara, CA 93106

and NBER

olivier@econ.ucsb.edu 


\section{Introduction}

One of the greatest contributions of applied econometrics has been to provide empirical methods for estimating the economic consequences of anticipated future changes. The canonical application centers around the estimation of cross-sectional hedonic regressions using market outcome data to estimate the response of asset prices to exogenous variation in a variable of interest and that is expected to change in the future (due to change in policy, regulations, or other factors). ${ }^{1}$ With the estimated relationship in hand, it is straightforward to predict the costs or benefits associated with expected future changes in any variable of interest, i.e. to project the expected change in the state variable on the empirically estimated price gradient. This broad approach has been used in prominent papers to value potential future regulatory changes to the Clean Air Act (Chay and Greenstone 2005), policies that are expected to reduce crime rates (Linden and Rockoff 2008), and policies that are expected to improve local school quality (Black 1999), among numerous others.

One branch of this literature that has had a tremendous policy impact focuses on the economic consequences of climate change. In that context, the method is known as the Ricardian approach, following the seminal paper of Mendelsohn, Nordhaus, and Shaw (1994) (hereafter MNS). The key empirical component of the Ricardian approach is a cross-sectional regression of land values on historical climate conditions and other relevant variables to estimate how the value of an asset (a parcel of land) is affected by climate. ${ }^{2}$ Using the Ricardian estimates of the climate-price gradient, the analyst then uses scientific predictions of future changes in temperature and precipitation (and possibly other climate variables) to estimate the economic impact of climate change.

These hedonic analyses contain an important implicit assumption that economic assets do not already capitalize the future change that is now anticipated by the researcher. In the climate change example, this amounts to assuming that current land markets fail to account for climate change forecasts. While this was quite plausible for land market data in the 1980's and 1990's, it is reasonable to wonder whether that is still the case.

\footnotetext{
1. Most empirical applications build on the seminal work of Rosen (1974) and derive estimates of household willingness to pay for an array non-market amenities.

2. The Ricardian regression specification typically includes historical average precipitation and historical average temperature. For illustrative power, our theoretical exposition focusses on a single climate variable: average temperature. The critique we present in this paper applies to other climate variables that enter the land pricing equation, such as precipitation, and are accounted for in our empirical work. Deschênes and Greenstone (2007) and Massetti and Mendelsohn (2011) have extended the cross-sectional Ricardian method to the panel data framework.
} 
If land markets already capitalize available information on climate change, then the standard Ricardian approach will be biased. When a valuation method relies on asset markets, it must consider the fact that current asset prices rationally account for expected future changes in all relevant variables that determine its value (e.g., the state variables). As we show, ignoring the forward-looking nature of asset markets leads to a mis-specified empirical regression model, biased estimates of the price gradients for the relevant state variables, and ultimately biased predictions regarding the economic effects of the anticipated future changes in the state variables. We illustrate these issues in the context of the Ricardian approach and argue that future applications of the method must be modified to account for the simple, yet powerful, stylized fact that asset markets capitalize information. Put simply, because climate information is so pervasive, current land prices should reflect expected future climate, not just the currently observed climate.

Our review of the literature indicates that existing theoretical presentations and empirical implementations of the Ricardian approach indeed implicitly assume that the current asset market ignores possible future change in the climate or other state variables. ${ }^{3}$ We label those applications the myopic Ricardian approach. We show that this critique applies generally, except when either (1) the market does not capitalize any expectation of future change in climate or other determinants of land value, or (2) a technical condition wherein the product of the correlation between current and future climate and the ratio of their standard deviations is precisely equal to one. To our knowledge, no theoretical or empirical treatment exists on this issue.

This paper attempts to make several contributions. First, we present a simple model of asset valuation that allows for market capitalization of information about future state variables to show that asset values should reflect expected future changes in the state variables. When applied to the Ricardian context of land values and climate, our model shows that observed land values should reflect expected future climate variables. This is in sharp contrast with current applications of the Ricardian method, which rely on regressions of land values on observed historical climate variables. ${ }^{4}$

3. The same is broadly true in the broader literature that has studied economic valuations of air quality, school quality, etc. A group of recent papers beginning with Kennan and Walker (2011) and Bishop and Murphy (2011) are an exception, providing a structural approach that accounts for moving frictions and expected future amenities or labor market conditions.

4. A recent search revealed that MNS has been cited in $>1,300$ publications on Google Scholar and has been used to examine the effects of climate change in various contexts; none of the most cited papers incorporate information. The Ricardian method has been used broadly to look at the agricultural effects of climate change worldwide: in Africa (Kurukulasuriya et al. 2006; Seo and Mendelsohn 2008b), in Asia (Seo, Mendelsohn, and Munasinghe 2005; Liu et al. 2004; Chang 2002), in South America (Seo and Mendelsohn 
Second, we derive conditions under which the bias occurs for two related misspecifications of the pricing equation. The first misspecification retains the dynamic structure of the pricing process. The second corresponds to the approach of much of the Ricardian literature, and is entirely static. We describe the theoretical direction of these biases and the factors that lead them to have a large or small magnitude. The direction and magnitude of the bias hinge on the correlation between past and future states and on the variances of those states (climate in our example) and can generally be positive, negative, or zero. Bias is likely to occur anytime that climate change is expected to cause different changes in different places.

Third, we derive a flexible, straightforward correction that can be implemented with readily available data and can accommodate a degree of uncertainty as to precisely what information the market regards as the forecast. This approach accounts for market information, the timing of information acquisition, the stream of revenues associated with various state variables, and the possible divergence of information between the market and the analyst. Without such a correction, the myopic Ricardian method generally leads to biased estimates of the relationship between climate and land values, and thus biased predictions about the future economic consequences of climate change.

We illustrate these issues and implement the proposed forward-looking Ricardian regression to the now seminal framework of MNS. This illustration provides the first empirical analysis that documents to what extent current land markets are capitalizing future expectations about climate. We find clear evidence that current asset markets capitalize information about the future climate, suggesting that estimates of climate change impacts in the literature reflect the bias created by using the myopic Ricardian model. This bias is economically important: depending on the choice of future climate trajectory, applying the myopic Ricardian approach (i.e. ignoring current market information about future climate change) could underestimate the damage from climate change by $36 \%$ to $66 \%$. Finally, using a new county-level data set on perceptions over climate change from Howe et al. (2015), we find that land values are more strongly related to future climate predictions (as opposed to past climate normals) in counties with higher beliefs in climate change.

2008a), and in Europe (Madison 2000; Reidsma, Ewert, and Oude Lansink 2007). These, and Ricardian studies in general, either utilize the value of agricultural production directly or as estimated from the value of agricultural land. Our critique is most relevant when these estimates rely on land values, but apply anytime information may play a role in asset price formation. 


\section{The role of information in the Ricardian literature}

In a competitive setting, rational agents with well-defined property rights price assets to reflect the expected stream of rents generated from the asset. In non-commodity markets, variation in the characteristics of an asset determines the market valuation of the asset and thus the price at which similar assets are sold. A large literature utilizes this sort of variation to estimate the willingness to pay for a wide variety of non-transacted goods. Using market data to determine the otherwise unobservable preferences on packages of characteristics of agents with respect to non-transacted goods is termed hedonic valuation (Rosen 1974). This methodology has been extensively used to estimate the economic value of climate and other non-transacted amenities in land and housing markets (Albouy et al. 2016; Blomquist, Berger, and Hoehn 1988; Cragg and Kahn 1997; Roback 1982; Sinha and Cropper 2013).

The hedonic method has also been applied widely to study the effect of various climate amenities on agricultural land prices. By estimating these effects, the monetary impact of changes in future amenity levels (like climate) can be estimated. By assuming that farmers are profit maximizing and so adjust farming decisions in response to shifts in amenity levels, the hedonic method recalls David Ricardo's seminal work and is commonly referred to as the Ricardian method. This method, first proposed in MNS, is based on a crosssectional regression of land values on a variety of historical climate variables (such as average temperature and precipitation) and interprets the results as the effect of these variables on agricultural productivity. The impact of climate change is calculated by taking the linear combination of these regression coefficients and predicted (rather than historical) future climate. MNS concluded that a uniform 5 degree change in temperature and $8 \%$ increase in precipitation is estimated to cause from a $4-5 \%$ loss to a $1 \%$ gain in farmland values (a loss of $\$ 6-8$ billion per year to a gain of $\$ 1-2$ billion per year, based on 1982 revenue), depending on weighting scheme.

Agriculture in the western portion of the United States is predominately irrigated, and western farmers respond in a qualitatively different manner to climate conditions than in regions dominated by non-irrigated (dryland) agriculture. Schlenker, Hanemann, and Fisher (2005) and Schlenker, Hanemann, and Fisher (2006) refine MNS by restricting attention to dryland counties, as well as providing agronomically motivated functional relationships between climate variables. They find the impact of climate change in dryland counties to be between $-\$ 5$ and $-\$ 5.3$ billion per year (1982 dollars) (Schlenker, Hanemann, and Fisher 2005), and between $-\$ 3.1$ and $-\$ 7.2$ billion per year using improved weather specifications (Schlenker, 
Hanemann, and Fisher 2006). ${ }^{5}$ The hedonic approach in this context can be sensitive to specification, potentially indicating misspecification or omitted variables. Deschênes and Greenstone $(2007,2012)$ approach the question of climate change's effect on US agriculture in a different manner, using annual variation in temperature to identify a lower bound on the effect of climate change. They conclude that climate change will lead to a reduction of agricultural profits by $\$ 4.5$ billion per year (in 2002 dollars) by the end of the century.

While asset markets generally capitalize the expected future levels of relevant state variables, the timing at which information about future changes is absorbed by the market is critical. In the context of global climate change, the accumulation and dissemination of evidence regarding the predicted rise in temperatures began in the 1990s. For example, the IPCC's First Assessment Report was published in 1990 and predicted an increase in global mean temperature of about 0.3 Celsius per decade. Thus, land value data from the preceding decades are unlikely to reflect future climate change. As public knowledge about climate change advanced over the 1990s and 2000s, it is reasonable to wonder whether these anticipated impacts are reflected in current land values. ${ }^{6}$ This is the key premise underlying this paper.

In Ricardian studies that use the US Census of Agriculture (Mendelsohn, Nordhaus, and Shaw 1994; Schlenker, Hanemann, and Fisher 2005, 2006; Deschênes and Greenstone 2007), the value of agricultural land is farmers' (self-reported) estimate of the market value of the land. This value capitalizes information about future market and amenity conditions. The intuition underlying this is straightforward: suppose it is well known that a parcel of farmland would experience a large exogenous decrease in soil quality the year after a proposed sale. Its value in a market with symmetric information and rational actors would be lower than an otherwise equivalent parcel with constant soil quality. Failure to incorporate information into the hedonic model amounts to an implicit assumption that market participants are myopic. In the Ricardian literature, this is akin to assuming that farmers (or any participant in land markets) are myopic in their valuation of land even while maintaining the assumption of sophisticated profit-maximizing behavior. Market prices for a productive asset reflect beliefs about the future productivity (or stream or benefits) of the asset. That assets should be

5. Their analysis uses 1982 dollars - throughout the present paper we adjust inputs to 2005 dollars using a CPI adjustment.

6. The initial application of the Ricardian approach (MNS) was based on land market data from 1978 and 1982. As a result, the results in MNS are most likely immune to the critique presented in this paper. However, the continued application of the myopic Ricardian method to market data from the 2000s and 2010s may no longer be appropriate if markets capitalize expectations about changing future climates, as our empirical results will suggest. 
priced to reflect the discounted flow of profits in combination with expected future sale price is central to arbitrage pricing and dividend discount models in finance.

The notion that land markets capitalize expected rents regarding land development, subsidies, and irrigation is recognized in related literature. In particular, the option to develop land for non-agricultural use greatly influences agricultural land value. For example, Plantinga, Lubowski, and Stavins (2002) estimate that $80 \%$ of agricultural land values in New Jersey are attributable to development potential. ${ }^{7}$ Irrigation, and expectations related to water withdrawals therefrom, impact land prices significantly in the relatively dry region above the Ogallala aquifer (Hornbeck and Keskin 2014). Land markets have also been shown to capitalize irrigation subsidies, the value of which may be up to two and a half times the value of the land (Schlenker, Hanemann, and Fisher 2006). This, in combination with uncertainty over irrigation related property rights dictates restricting attention to non-irrigated counties (Schlenker, Hanemann, and Fisher 2005, 2006).

While the capitalization of potential land development and irrigation rights in agricultural land market has been demonstrated empirically, our reading of the literature indicates that expectations over future climate have not been incorporated when estimating the economic impacts of climate change. This is despite explicit discussion of land value formation in the Ricardian literature. For example, MNS note "[f]arm value is the present value of future rents," and Mendelsohn, Nordhaus, and Shaw (1996) argue that their covariates control for "speculative future land uses." Schlenker, Hanemann, and Fisher (2005) exclude urban counties because of concerns that development potential would confound estimates of the climate-price gradient. Schlenker, Hanemann, and Fisher (2006) compare coefficients on the hedonic model from 1982 and 1997 to conclude that farmer expectations had not changed over that period. While this was quite plausible in 1997 (with data collected primarily in 1995), public knowledge of climate change has increased dramatically in recent decades as scientific forecasting of impacts has become more sophisticated and widely disseminated.

A recent empirical literature has begun to address and model the role of uncertainty and future predictions in consumer behavior, generally by finding proxies for the probability that some uncertain (binary) event will occur. These proxies serve to approximate consumer or market perception of risk. Meng (2013) uses prediction market prices to capture market beliefs relating to the risk of climate regulation in order estimate the cost to firms of climate change legislation. Gallagher (2014) models learning about uncertain, infrequent flooding

7. In studies of agricultural land prices, the effect of development pressure is controlled for by including population density or distance to urban centers as controls, or by excluding urban and suburban counties. 
events in the United States. Davis (2004) finds the marginal willingness to pay to avoid the risk of pediatric leukemia using hedonic techniques. Deryugina (2013) finds that survey respondents update beliefs about climate change in a rational manner. Our paper extends and complements this new focus on incorporating the effects of information into applied economic analysis.

\section{Asset prices and information}

Here we describe a simple model of an asset price $(P)$ based on the stream of rents it generates $(p)$ when forecasts of the future state variables are available to the market. By state, we refer to potentially time-varying characteristics of an asset that contribute to price formation. In our motivating application, the state variable is climate. Climate has a strong agronomic connection to the agricultural profits that can produced on a given parcel of land. Similar parcels of land under different climate regimes produce different rents, and thus have different prices.

We treat land as an asset that is rented to firms in order to produce globally traded commodities. A firm can produce any of $K$ products on a parcel of land at any time $t$. Use $k$ generates gross revenue $v_{k t}\left(x, \ell, \mathcal{S}_{t}\right)$ that depends on inputs $x$, land characteristics $\ell$, and the state variable $\mathcal{S}_{t}$; the cost of using input vector $x$ is captured by $c_{t}(x)$. For any use $k$, firms select inputs to maximize net revenue:

$$
r_{k t}(\mathcal{S} ; \ell)=\max _{x} v_{k t}\left(x, \ell, \mathcal{S}_{t}\right)-c_{t}(x)
$$

The subscripted $t$ captures the fact that factors influencing revenue and costs (i.e. prices) may be time varying. Perfect competition among producers implies zero profits for firms on any parcel of land and ensures that firms chose the use of land that maximizes net revenue. ${ }^{8}$ The zero profit condition pins down the rental rate, $p$, of the parcel (suppressing the fixed land characteristics so that $\left.r_{k t}(\mathcal{S} ; \ell)=r_{k t}(\mathcal{S})\right)$ :

$$
\max _{k}\left\{r_{1 t}\left(\mathcal{S}_{t}\right), \ldots, r_{K t}\left(\mathcal{S}_{t}\right)\right\}-p_{t}\left(\mathcal{S}_{t}\right)=0
$$

where we have implicitly assumed that there are zero adjustment costs between uses. While this may be a strong assumption for sectors with high levels of fixed capital, in agriculture

8. In this framework, incumbent landowners are the residual claimants of the economy and the value of their assets could be used to calculate welfare in a general equilibrium analysis. 
many non-land inputs are variable and change year to year (seed, water, fertilizer). In fact, Kelly, Kolstad, and Mitchell (2005) find that adjustment costs in the US midwest for agricultural in response to climate change are small, well under $1 \%$ of the asset value of land. Burke and Emerick (2013) identify little adjustment in agricultural practices to changing climate, either because there are limited options for adjustment or because adjustments costs are too high to be profitably employed. Excluding adjustment costs allows us to collapse dynamic pricing concerns into simple, net present value indices for future climate. ${ }^{9}$

Land is bought and sold in a competitive market, and it is assumed there are no arbitrage opportunities. Thus the price $P$ of the parcel is the present discounted value of future rents and depends on the evolution of the state variable. Given a deterministic future sequence of states $\left\{\mathcal{S}_{0}, \mathcal{S}_{1}, \ldots\right\}$, the asset price is

$$
P\left(\mathcal{S}_{0}, \mathcal{S}_{1}, \ldots\right)=\sum_{t=0}^{\infty} p_{t}\left(\mathcal{S}_{t}\right) \delta^{t}
$$

where $\delta \in[0,1)$ is the discount factor. Thus, the price of land is simply a function of the stream of rents associated with land rental. Equation (3) is a discrete time version of the classic capitalization model of Ricardo (1821) treating land as a fixed factor of production (Nickerson and Zhang 2014). Rearranging the zero profit condition (Equation 2) reveals that the rental rate $p$ is equal to the envelope of land uses. As in MNS, we assume that this forms a continuous, differentiable function of the state variable. This permits approximation of price with standard linear (and quadratic) predictors. Denote the linear approximation of the rental rate by:

$$
p_{t}\left(\mathcal{S}_{t}\right) \approx a+b \mathcal{S}_{t}
$$

where $b=\partial p / \partial \mathcal{S}$ is the instantaneous change in rental rates due to shifts in the state variable, and $a$ captures the value of fixed determinants of $p \cdot{ }^{10}$ For simplicity, we model $p$ as a constant function up to the state variable. ${ }^{11}$ For a deterministic path of future states, the price of the asset at time $t=0$ is approximated by the present discounted value of the

9. Several papers examine adjustment costs in the context of residential relocation: Bayer et al. (2016); Bishop and Murphy (2011); Bishop (2015); Kennan and Walker (2011).

10. We implement this as a quadratic approximation in multiple climate variables, following MNS. Note that this can interpreted as a restricted multivariate Taylor series approximation with no interaction between different climate variables. In principal, estimation could allow for these interactions. We abstain to maintain comparability with MNS and the related literature.

11. Relaxing this assumption would require general equilibrium analysis of the changes in crop prices and the prices of inputs, which we consider beyond the scope of this paper. 
linear approximation of future rents:

$$
P\left(\mathcal{S}_{0}, \mathcal{S}_{1}, \ldots\right) \approx \sum_{t=0}^{\infty}\left(a+b \mathcal{S}_{t}\right) \delta^{t}
$$

Note that in the case of a constant state $\mathcal{S}_{0}$, the price of the asset is simply $P=a D+b D \mathcal{S}_{0}$ where $D \equiv \sum_{t=0}^{\infty} \delta^{t}=1 /(1-\delta)$.

Now suppose that the future sequence of states is uncertain, but that the market anticipates the possibility of change in the state. Market information about the evolution of states at time $t=0$ is public and denoted by $\Sigma$. Belief formation over the evolution of the state space is the process of mapping information to a set of probability spaces. These probability spaces share support $\Omega$ (the state space) and an appropriate $\sigma$-algebra, but possess potentially different probability measures for each period from $t=0$ until the market's horizon $T$ periods later. ${ }^{12}$ Beliefs about period $t \neq 0$ formed in period $t=0$ are represented by a probability density function over states: $f_{t}$. Thus, market beliefs are the mapping:

$$
\Sigma \rightarrow\left\{f_{0}, f_{1}, \ldots, f_{T}\right\}
$$

The market information set is the product of a series of distributions from the current period into the future; given a set of realizations (one from each period), prices would be deterministic. Market beliefs, in the form of this sequence of distributions, can take any path. For example, if climate change implied local warming with constant variance, then $f_{t+1}$ would stochastically dominate $f_{t}$ in each period. Under no arbitrage, the market capitalizes this information in an efficient manner and the pricing function can be recast as an expectation that now depends on the information set $\Sigma$ :

$$
P(\Sigma)=\mathbb{E}_{0}\left[\sum_{t=0}^{\infty} \delta^{t} p\left(\mathcal{S}_{t}\right)\right]=\sum_{t=0}^{\infty}\left(\delta^{t} \int_{s \in \Omega} p(s) f_{t}(s) d s\right)
$$

Rewriting this in terms of the linear approximation and simplifying gives:

$$
P(\Sigma)=a D+b \sum_{t=0}^{\infty} \delta^{t} \mathbb{E}_{0}\left[\mathcal{S}_{t}\right]
$$

Under uncertainty about future states, our implicit assumption of risk neutrality implies

12. In principle, $T$ could be $\infty$. In practice, we restrict $T$ to be about 100 years. For reasonable values of $\delta$, the role of periods beyond 100 years in the future is minimal. 
that the market prices the asset according to the expectation of the evolution of the state. ${ }^{13}$ Thus, only the path of mean beliefs determine prices.

Under the assumptions of this simple model, the path of mean forecasted states $\left\{\mathbb{E}_{0}\left[\mathcal{S}_{t}\right]\right\}_{t=0}^{\infty}$ and knowledge of the slope of the rental function $p$ with respect to the state are sufficient to describe prices. Further, if asset rental rate Equation (4) is quadratic in the state variable (as modeled in MNS and virtually all other applications of the Ricardian method), a variant of this sufficiency holds with one additional assumption: If $\operatorname{Var}\left(\mathcal{S}_{t}\right)$ is constant (or exogenous) across observations, then again only the mean belief path matters. ${ }^{14}$ However, if places with systematically higher draws of $\mathcal{S}_{t}$ also experience systematically higher or lower variance than $\mathcal{S}_{t}$, then Equation (6) should be augmented to include a variance and covariance terms, as in Kelly, Kolstad, and Mitchell (2005). Instead, we include spatially delineated fixed effects in our empirical analysis to limit the impacts of the variance term.

Consider two different scenarios, one describing a world with a constant state $\left(\mathcal{S}_{t}=\mathcal{S}_{0}\right.$ $\forall t$ ) and the other where a distribution of potential state changes is anticipated. These scenarios motivate two different models to represent land prices. As we show, both models differ from the standard Ricardian method. To proceed, it will be convenient to define a simple index, the infinite stream of states associated with each of the two scenarios. ${ }^{15}$ Let

$$
\begin{aligned}
I & \equiv \sum_{t=0}^{\infty} \mathcal{S}_{0} \delta^{t} \quad \text { (i.e., the No Change index) } \\
Y & \equiv \sum_{t=0}^{\infty} \mathbb{E}_{0}\left[\mathcal{S}_{t}\right] \delta^{t} \quad \text { (i.e., the Mean Forecast index) }
\end{aligned}
$$

Each of these indices captures, in a single variable, the present value magnitude of a forecast about the future state. Substituting into Equation (6), the No Change and Mean Forecast indices can be used to construct two different asset prices:

$$
\begin{aligned}
& P(I) \approx a D+b I \quad \text { (the No Change asset price) } \\
& P(Y) \approx a D+b Y \quad \text { (the Mean Forecast asset price) }
\end{aligned}
$$

13. While individual farmers may be risk averse, the presence of crop insurance means that they are somewhat protected from annual fluctuations in weather, mitigating the effects of risk. Further, we use spatially delineated fixed effects to control for the potentially correlated effects of variability; see below.

14. In the quadratic case, $P=\sum_{t=0}^{\infty} \delta^{t}\left(a+b_{0} \mathbb{E}\left[\mathcal{S}_{t}\right]+b_{1} \mathbb{E}\left[\mathcal{S}_{t}^{2}\right]\right)$, which can be expressed as $P=\sum_{t=0}^{\infty} \delta^{t}(a+$ $\left.b_{0} \mathbb{E}\left[\mathcal{S}_{t}\right]+b_{1}\left(\operatorname{Var}\left[\mathcal{S}_{t}\right]+\mathbb{E}\left[\mathcal{S}_{t}\right]^{2}\right)\right)$. We include the squared expectation term in our specifications. Thus only the variance term is troubling, and this impacts empirics only if the variance of beliefs about climate in each year varies across location in a way that is systematically correlated with expected climate.

15. The only assumption needed to guarantee that this is feasible for $\delta<1$ is that $\left|\lim _{t \rightarrow \infty} \mathbb{E}\left[\mathcal{S}_{t}\right]\right|<\infty$. 
Note the correspondence between the prices associated with each scenario: $P(Y)=P(I)-$ $b(I-Y)$. The difference $(I-Y)$ captures deviations of future expectations from the current state. If markets do capitalize expectations, observed asset price data correspond to $P(Y)$. In that case, the $N o$ Change asset price $P(I)$ is unobserved. Equation (10) can be used as the basis for empirical analysis based on observed land value data:

$$
P_{i}\left(Y_{i}\right)=\alpha+b Y_{i}+\varepsilon_{i}
$$

where $i$ indexes observations, $\alpha=a D$, and $\varepsilon_{i}$ captures unobserved determinants of prices that are uncorrelated with $Y_{i}$.

\section{The Ricardian approach in context}

As stated earlier, when markets capitalize expectations, observed asset price data correspond to $P(Y)$, and $P(I)$ is unobserved. As a result, interchanging prices between Equations (9) and (10) generally misspecifies the theoretical relationship between price and states. In contrast, the standard Ricardian regression ignores the market expectation about the future climate specifies a model linking land values to observed historical climate: ${ }^{16}$

$$
P_{i}\left(Y_{i}\right)=\alpha+\beta \mathcal{S}_{0 i}+u_{i}
$$

Thus, the standard Ricardian regression assumes that the state is constant and reports coefficients $\beta$ that describe the marginal effect of the state on net present value of rents. The difference between this coefficient and $b$ (the marginal effect of the state on single period rents) warrants additional caution when predicting the impacts of change in a state: impacts should either be expressed in annual terms or in net present value. This scaling issue can be trivially addressed. We next show how misspecifying Equation (12) by replacing $Y_{i}$ by $I_{i}$ (or $\mathcal{S}_{0 i}$ ) leads to bias in the empirical estimate of the parameter $b$.

\subsection{Ignoring beliefs biases estimates of Ricardian parameters}

As the previous section shows, the standard Ricardian approach misspecifies the theoreticallly correct land value equation when markets capitalize expectations about future climate.

16. Before proceeding, we make a brief note on the form of this regression. The dependent variable in this analysis is the price of land per acre, as in MNS. Many other analyses use the natural logarithm of price per acre. However, the additive nature of the present discounted value calculations precludes using that transformation. Estimates using log price are similar to those reported in our empirical analysis. 
This results in an omitted variable bias in empirical implementations. To develop intuition about this bias, we first derive a simple analytic expression for its magnitude and direction when the misspecified equation utilizes the present value magnitude of a forecast (i.e., using $I_{i}$ instead of $Y_{i}$ to predict land values). The algebraic simplicity of this bias calculation is muddied when considering the bias generated by estimating the traditional Ricardian regression (where the single state $\mathcal{S}_{0 i}$ is substituted for present value index $I_{i}$ ), but the intuition is similar.

Suppose that an analyst takes full account of the dynamics of asset markets (and so uses $I_{i}$ instead of $\mathcal{S}_{0 i}$ ), but implicitly assumes that the market fails to capitalize any expectation about future climate. In that setting, the analyst would incorrectly estimate the marginal impacts of a constant state when using prices that reflect expectations:

$$
P_{i}\left(Y_{i}\right)=\alpha+b I_{i}+e_{i}
$$

The resulting parameter estimates of $b$ are biased owing to an omitted variable problem. Substituting from Equation (11) it is straightforward to show that $e_{i}=\varepsilon_{i}+b\left(Y_{i}-I_{i}\right)$. Denote the OLS estimator of $b$ by $\tilde{b}$. It follows that:

$$
\tilde{b} \stackrel{p}{\rightarrow} \frac{\operatorname{Cov}\left(I_{i}, P_{i}\left(Y_{i}\right)\right)}{V\left(I_{i}\right)}=\frac{\operatorname{Cov}\left(I_{i}, \alpha+b I_{i}+\varepsilon_{i}+b\left(Y_{i}-I_{i}\right)\right)}{V\left(I_{i}\right)}=b \frac{\operatorname{Cov}\left(I_{i}, Y_{i}\right)}{V\left(I_{i}\right)}=b \frac{\rho_{I Y} \sigma_{Y}}{\sigma_{I}}
$$

where $\rho_{I Y}$ is the correlation between the No Change and Mean Forecast descriptions of the state, $\sigma_{I}$ is the standard deviation of $I_{i}$, and $\sigma_{Y}$ is the standard deviation of $Y_{i}{ }^{17}$ Given a sample of data on $I_{i}$ and $Y_{i}$ the standard deviation and correlation coefficient $\sigma_{I}, \sigma_{Y}$, and $\rho_{I Y}$ can all be estimated. Thus the magnitude and sign of the bias in the empirical estimate of $b$ reflects the joint distribution of the forecasts $I_{i}$ and $Y_{i}$. This leads to the following observation:

Result 1. The incorrect specification of the land value equation that ignores expectations results in a consistent estimate of $b(\tilde{b} \stackrel{p}{\rightarrow} b)$ only if $\rho_{I Y} \sigma_{Y} / \sigma_{I}=1$. In general, the relative bias is equal to $\rho_{I Y} \sigma_{Y} / \sigma_{I}$.

This formula for bias deserves a few notes. First, there is one special case where $\rho_{I Y} \sigma_{Y} / \sigma_{I}=1$ by necessity. When the Mean Forecast description of the state of the world is simply the No Change description plus a constant additive term, $\rho_{I Y}=1$ and $\sigma_{I}=\sigma_{Y}$,

17. Extending the bias calculation to the multivariate case is slightly less straightforward as it involves the covariances of omitted variables. The intuition is similar, however. 
so relative bias is equal to one and $b$ is identified by a regression of $P_{i}\left(Y_{i}\right)$ on $I_{i}$. Second, most climate change forecasts do not predict a 'reversal of fortunes': warmer locales will likely become warmer than cooler locales, implying that $0<\rho_{I Y}<1$. Thus, if the ratio of standard deviations $\sigma_{Y} / \sigma_{I}$ is less than one, the bias in the standard Ricardian regression will lead to an understatement of the climate change effects. In particular, if current and predicted climate are not very correlated (as $\left|\rho_{I Y}\right|$ approaches 0 ), current climate is a poor proxy for predicted climate and $\tilde{b}$ is attenuated. ${ }^{18}$ At the same time, it is possible that the method overstates damages if $\sigma_{Y} / \sigma_{I}>>1$, as would be the case if cross-sectional variation in predicted climate were much larger than in current climate.

Suppose, instead, that the analyst ignores dynamics altogether and estimates the standard Ricardian model directly (Equation 12). If this regression were correctly specified, then there would be no issue as it we be easy to transform estimates of the marginal net present value of the state to marginal rental impacts: $\hat{b}=\hat{\beta} / D$. However, when Equation (12) is estimated but Equation (11) describes the true pricing process (due to that market's capitalization of expectations about future states), then $\hat{\beta}$ is biased and dividing by $D$ does not return a consistent estimate for $b$. As long as $\mathcal{S}_{0 i}$ is correlated with $Y_{i}$, the standard application of the Ricardian method will produce biased estimates of $\beta$ (or $b$ ) due to an omitted variables bias similar to that in Equation (14).

To illustrate this result, we derive the correlation between $\mathcal{S}_{0 i}$ and $Y_{i}$. This requires assuming a model describing how expectations about the future state are formed so that we can derive a practical expression for $Y$ that can be implemented with available data. For simplicity, consider the case where beliefs have discrete support, assigning probabilities with positive measure to a finite number of (potentially time-varying) values in the state space. ${ }^{19}$ Equation (11) can be partitioned into a component that depends on the current state $\left(\mathcal{S}_{0 i}\right)$, and a component derived from alternative expectations about $\mathcal{S}_{t i}$. Define by $\pi_{t}=\operatorname{Pr}\left(\mathcal{S}_{t i}=\mathcal{S}_{0 i}\right)$ the probability that the current state is realized in period $t$. Then:

$$
Y_{i}=\left(\sum_{t=0}^{\infty} \delta^{t} \pi_{t}\right) \mathcal{S}_{0 i}+\left(\sum_{t=0}^{\infty} \delta^{t}\left(1-\pi_{t}\right) \mathbb{E}\left[\mathcal{S}_{t i} \mid \mathcal{S}_{t i} \neq \mathcal{S}_{0 i}\right]\right)
$$

18. In fact, if $\rho_{I Y}=0$, then $\tilde{b}=0$ regardless of $b$ or $\sigma_{I}, \sigma_{I}$.

19. In the climate change example, this would be like assigning a (potentially time-varying) probability to each path of climate change available in the IPCC reports. 
and so

$$
P_{i}\left(Y_{i}\right)=\alpha+b\left(\sum_{t=0}^{\infty} \delta^{t} \pi_{t}\right) \mathcal{S}_{0 i}+b\left(\sum_{t=0}^{\infty} \delta^{t}\left(1-\pi_{t}\right) \mathbb{E}\left[\mathcal{S}_{t i} \mid \mathcal{S}_{t i} \neq \mathcal{S}_{0 i}\right]\right)+\varepsilon_{i}^{Y}
$$

If the analyst proceeds following the standard Ricardian approach (omitting the second term in parentheses in the equation above), the bias in the regression estimate of $\beta$ is given by:

$$
\begin{aligned}
\hat{\beta} \stackrel{p}{\rightarrow} \frac{\operatorname{Cov}\left(\mathcal{S}_{0 i}, b\left(\sum_{t=0}^{\infty} \delta^{t} \pi_{t}\right) \mathcal{S}_{0 i}+b\left(\sum_{t=0}^{\infty} \delta^{t}\left(1-\pi_{t}\right) \mathbb{E}\left[\mathcal{S}_{t i} \mid \mathcal{S}_{t i} \neq \mathcal{S}_{0 i}\right]\right)\right)}{V\left(\mathcal{S}_{0 i}\right)} \\
=b \sum_{t=0}^{\infty} \delta^{t}\left(\pi_{t}+\left(1-\pi_{t}\right) \operatorname{Corr}\left(\mathcal{S}_{0}, \mathbb{E}\left[\mathcal{S}_{t} \mid \mathcal{S}_{t} \neq \mathcal{S}_{0}\right]\right) \sqrt{\frac{V\left(\mathbb{E}\left[\mathcal{S}_{t} \mid \mathcal{S}_{t} \neq \mathcal{S}_{0}\right]\right)}{V\left(\mathcal{S}_{0}\right)}}\right)
\end{aligned}
$$

This reveals that the parameter estimate $\hat{\beta}$ depends on the true parameter $b$ as well as the magnitude of and confidence in alternative forecasts.

Result 2. The standard Ricardian approach gives a consistent estimate of $\beta(\widehat{\beta} \stackrel{p}{\rightarrow} \beta)$ only if one or both of the following are true: (1) The market places no probability on the possibility of change $\left(1-\pi_{t}=0\right)$ for all $t$, or (2) the product of the correlation term and ratio of standard deviations in Equation (16) precisely equals one. Note that in that case $\widehat{\beta} \stackrel{p}{\rightarrow} \beta \equiv b D$.

Both of these conditions seem unlikely in most applications, even in scenarios that intuition from standard OLS indicates should not cause concern. For example, (i) even if the omitted variable (representing mean alternative beliefs) is orthogonal to the observed (historical) covariate, there could still be bias. There could still be bias (ii) even if there is no variation in the expected state across space. In both cases, estimates are attenuated. ${ }^{20}$ Just as with Result 1, there is one important case in which bias does not arise: If beliefs are the current state plus an additive term that is constant across observations in each period. ${ }^{21}$

We can use this machinery to hypothesize about the direction of this bias. Recall that $\beta \equiv b \sum_{t=0}^{\infty} \delta^{t}=b D$, and note that $V\left(\mathcal{S}_{t}\right)$ is an upper bound on the numerator of the term under that radical. In general the term under the radical can be any nonnegative value, however, for median climate models it is reasonable to imagine this as roughly equal to one. $^{22}$ The correlation term is strictly less than one, and likely positive. Thus, in most

20. If (i) were true, $\operatorname{Corr}\left(\mathcal{S}_{0}, \mathbb{E}\left[\mathcal{S}_{t} \mid \mathcal{S}_{t} \neq \mathcal{S}_{0}\right]\right)=0$. If (ii) were true, then $V\left(\mathcal{S}_{t}\right)=0$. In either case, $\hat{\beta} \stackrel{p}{\rightarrow} b \sum_{t=0}^{\infty} \delta^{t} \pi_{t} \leq b D$.

21. In this case, $V\left(\mathbb{E}\left[\mathcal{S}_{t} \mid \mathcal{S}_{t} \neq \mathcal{S}_{0}\right]\right)=V\left(\mathcal{S}_{0}\right)$ and $\operatorname{Corr}\left(\mathcal{S}_{0}, \mathbb{E}\left[\mathcal{S}_{t} \mid \mathcal{S}_{t} \neq \mathcal{S}_{0}\right]\right)=1$ in each period, so $\hat{\beta} \stackrel{p}{\rightarrow}$ $b \sum_{t=0}^{\infty} \delta^{t}\left(\pi_{t}+\left(1-\pi_{t}\right)\right)=b D$ and there is no bias.

22. In the Hadley data, the ratio of average standard deviations is roughly 0.9-0.95, although extreme 
cases estimates of $\beta$ that fail to account for expectation will be biased toward zero and the effect underestimated. Indeed, our empirical example indicates that the myopic approach understates effects and impacts.

\subsection{The economic cost of anticipated future change}

The information contained in prices can be used to determine both the net present value (NPV) impact of change in the state (e.g., change in the climate) as well as annual impacts to rents. In many ways, the NPV impact of change is the more policy relevant one, for example, in cost-benefit analysis. We therefore focus on the NPV impacts. While it is straightforward to scale between the two impacts given an appropriate measure of $b$, doing so requires an understanding of the market's discount rate, $\delta$. Furthermore, it may be that society's discount rate differs dramatically from that of the market, a fact which should be accounted for in analysis that compares outcomes and investments over the long term (Weitzman 1998). In our application, we assume that $\delta=0.03$ and investigate the robustness of the results to alternative discount rates.

Estimation of the economic costs of anticipated future change proceeds in two steps. The information (forecasts) used in the two steps can be identical or can differ. The first step is to estimate how asset prices responds to the expected path of future states; this amounts to correctly estimating $b$. For the second step, any set of forecasts can be used to derive counterfactual prices and estimate the impact of the change predicted by the forecast and some baseline state. In the case of climate change, estimation requires data on market beliefs about the mean path of climate variables. Given a consistent estimate $\hat{b}$, the impact of any path of state changes can then be predicted.

Predictions of the costs of future changes are made relative to some counterfactual. A relevant counterfactual compares outcomes under some forecast with outcomes had there been no change at all. In the climate change example, this is akin to comparing the prices of land given some change in climate with prices if climate were to remain constant. This counterfactual is found simply by estimating the unobserved prices associated with the No Change scenario, $P_{i}\left(I_{i}\right)$. Given data across observations on the current state $\mathcal{S}_{0 i}$, the expected path of future states $\left\{\mathbb{E}\left[\mathcal{S}_{t i}\right]\right\}_{\forall t}$, and prices $P_{i}\left(Y_{i}\right)$, it is straightforward to generate estimates $\widehat{P}_{i}\left(I_{i}\right)$. First, under the assumptions of our model, the following regression gives consistent values are closer to 0.5 (for winter precipitation) or 1.2 (summer precipitation). 
estimates of $b$ :

$$
P_{i}\left(Y_{i}\right)=\alpha+b Y_{i}+\varepsilon_{i}
$$

Estimates of the No Change price can be constructed with the No Change index and $\hat{b}$ :

$$
\widehat{P}_{i}\left(I_{i}\right)=P_{i}\left(Y_{i}\right)-\hat{b}\left(Y_{i}-I_{i}\right)
$$

Once an estimate of the counterfactual price is constructed, the impact of any change in state can be estimated. Recall however that the true $Y_{i}$ is unobserved. We return to this issue in Section 5.

The second step requires the analyst to consider a specific path of state changes. This could either be the same mean beliefs that market uses to form prices $\left(\mathbb{E}\left[\mathcal{S}_{t}\right]\right)$, or any other path that reflects either the mean path of an alternative set of beliefs or a different forecast. Let $\mathbb{E}\left[\mathcal{S}_{t}^{\prime}\right]$ represent the alternative set of beliefs or forecast. Define $Y^{\prime} \equiv \sum_{t=0}^{\infty} \mathbb{E}\left[\mathcal{S}_{t}^{\prime}\right] \delta^{t}$ to be an Alternative Forecast index constructed in the same manner as the Mean Forecast index. A counterfactual estimate of the price associated with the alternative forecast $Y_{i}^{\prime}$ can be obtained as follows:

$$
\widehat{P}_{i}\left(Y_{i}^{\prime}\right)=P_{i}\left(Y_{i}\right)+\hat{b}\left(Y_{i}^{\prime}-Y_{i}\right)
$$

The NPV of the predicted price change associated with the Alternative Forecast relative the No Change case for observation $i$ is simply $\widehat{P}_{i}\left(Y_{i}^{\prime}\right)-P_{i}\left(Y_{i}\right)=\hat{b}\left(Y_{i}^{\prime}-I_{i}\right)$. The aggregate NPV is obtained by summing across all observations:

$$
\text { NPV of impact given beliefs }\left\{f_{t}^{\prime}\right\}=\sum_{i} \hat{b}\left(Y_{i}^{\prime}-I_{i}\right)
$$

A particular case of interest is estimating the impact of change given the market's current beliefs. That is, it would be useful to estimate damages (or benefits) by comparing market expectations to counterfactual prices that reflect no change in state. This is special case of the aggregate impact formula above with $Y_{i}^{\prime}=Y$ for all observations. In this case, only one set of predicted prices needs to be used for this simplified estimate:

$$
\mathrm{NPV} \text { of impact given current market beliefs }=\sum_{i} P_{i}\left(Y_{i}\right)-\widehat{P}_{i}\left(I_{i}\right)=\sum_{i} \hat{b}\left(Y_{i}-I_{i}\right)
$$

The empirical analysis below will illustrate how this NPV can be estimated using readily available data. 


\subsubsection{Predicting prices vs. estimating impacts}

The preceding method for estimating the impact of anticipated changes should not be confused with techniques that predict prices. While our method utilizes 'counterfactual prices', these prices are formed from a well defined set of beliefs. Generally, predictions of how prices evolve require an assumption on the evolution of information. For example, if prices today are formed under information $\Sigma_{t=0}$, then prices tomorrow will be formed under information $\Sigma_{t=1}$. Thus, predicting prices tomorrow requires a prediction about $\Sigma_{t=1}$.

\section{Data}

The previous section shows that if the land market capitalizes expectations of future climate change, the standard Ricardian regression produces biased estimates. In the context of climate change, these damage estimates are important inputs into policy construction and debate. This and the following sections make three primary empirical contributions. First, we assemble a comprehensive dataset and test whether land markets capitalize readily available climate forecasts; this is the first test of its kind. Second, we use the results of the empirical analysis to re-estimate the economic impact of climate change on the US agricultural sector; this has important policy implications since current estimates of the damage from climate change contain the bias we have identified. Finally, to close the link between our theoretical and empirical findings, we estimate the bias in damage estimates that arises from (incorrectly) assuming that markets fail to capitalize predictions of future changes in climate by comparing predictions under both assumptions.

To implement the analysis, we have collected a data set with observations on agricultural land values for 2007, monthly average temperature and total precipitation (defined over the period the previous 30 years, i.e., 1976-2006), monthly climate predictions for the period 1900-2099 from two different climate models, soil quality indicators, as well as other determinants of land values. The goal is to construct an updated sample that mimics the one used by MNS. In addition, we also make use of data from the 1987-2007 Census of Agriculture data to further test some of the implications of the theoretical model. The next section describes these data and reports some summary statistics. 


\subsection{Census of Agriculture Data}

The primary data on agricultural land values are from the 2007 Census of Agriculture. By law, all farms and ranches that produce and sell (or normally would produce and sell) more than $\$ 1,000$ of agricultural products are required to submit a census form. Counties are the finest publicly available geographic unit of observation. The two key variables are the average values of agricultural land and buildings in a county (interpreted in the literature as farmland value, following MNS), and the total acres in farmland in each county. From these we construct average agricultural land values per acre of farmland. This is the dependent variable analyzed in most US applications of the Ricardian approach (Mendelsohn, Nordhaus, and Shaw 1994; Schlenker, Hanemann, and Fisher 2005, 2006; Deschênes and Greenstone 2007; Massetti and Mendelsohn 2011). We also use the same variables from the 1987-2007 Census of Agriculture in order to examine whether trends in estimated beliefs are broadly consistent with public information regarding climate change.

\subsection{Historical Weather Data}

Weather station data are drawn from the National Climatic Data Center (NCDC) Global Historical Climatology Network-Daily (GHCN-Daily), which is an integrated database of daily climate summaries from land surface stations that are subjected to a common set of quality assurance checks. According to the NCDC, GHCN-Daily contains the most complete collection of U.S. daily climate summaries available. The key variables for the analysis are the daily maximum and minimum temperature as well as the total daily precipitation. We select weather stations that have no missing records in any given year from 1976-2006. The station-level data is then aggregated to the county level by taking an inverse-distance weighted average of all the measurements from the selected stations that are located within a fixed $200 \mathrm{~km}$ radius of each county's centroid. The weight given to the measurements from a weather station is inversely proportional to the squared distance to the county centroid, so that closer stations are given more weight.

In order to construct historical climate variables, we follow the definitions in Massetti and Mendelsohn (2011). Specifically, we define the climate as the monthly average temperature and total precipitation calculated over the previous 30 years of the relevant weather variables, For example, for the 2007 Census of Agricultural data, the climate is defined over 19762006 and we implicitly assume the climate has not changed over this period. Furthermore, we follow convention and include a single measure of seasonal climate in the models for 
land values. Specifically, we include a quadratic in average temperature and precipitation for the winter (December-February), spring (March-May), summer (June-August), and fall (September-November).

\subsection{Future Climate Prediction Data}

All climate predictions are those used in the IPCC Fourth Assessment Report (Climate change 200\%: Synthesis report 2007). ${ }^{23}$ Our preferred set of climate predictions are obtained from the Hadley Centre Coupled Model, version 3 (Hadley 3), which is a coupled atmospheric-ocean general circulation model. The changes in temperature and precipitation in non-irrigated US states are roughly in the middle of the ensemble of models used for the IPCC Fourth Assessment Report (Burke and Emerick 2013). Predictions of climate change from this and other models used in the IPCC Fourth Assessment Report are available for several emission scenarios, corresponding to 'storylines' describing the way the world (population, economies, etc.) may develop over the next 100 years. We focus on the A2 scenario, a "business-as-usual" scenario, which is the proper baseline scenario to consider when evaluating policies to restrict greenhouse gas emissions. As such, predictions from the A2 scenario feature some of the largest predicted increases in global temperature.

Additional climate predictions are obtained from National Center for Atmospheric Research's Community Climate System Model (CCSM) 3, also a coupled atmospheric-ocean general circulation model included in the IPCC 4th Assessment Report (NCAR 2007). We focus on the A2 scenario to maintain consistency with the Hadley 3 model. Relative to Hadley 3, CCSM 3 predicts roughly the same level of warming with a greater increase in precipitation (Burke and Emerick 2013).

We use inverse-distance weighted averaging to assign gridded predictions to counties in the same manner as for station-level weather data. All grid points located in a pre-specified radius of a county's centroid are used to assign the climate prediction, with measurements from grid points located further away from the centroid receiving less weight. A radius of 200 kilometers ensures that every county gets a prediction. From these daily grid point level data we construct the same measures of seasonal climate for average temperature and total precipitation for every county and year. ${ }^{24}$

23. See http://www.ipcc-data.org/sim/gcm_monthly/SRES_AR4/index.html for all data on future climate predictions.

24. The inverse distance weighting approach to assign future climate to counties created a few anomalous assignments. These counties, primarily in Michigan, are excluded from this analysis. Consolidated cities in Virginia were also excluded. In total, 39 counties are excluded; full details are in Appendix I. 
Any given climate model may systematically over or under-predict climate in a particular geographical location. In order to correct for inherent aggregate model bias that takes effect at the county level, we use model predictions of historical climate and actual historical climate to create corrected climate predictions following Auffhammer et al. (2013). In particular, we utilize the climate of the 20th centuries runs used for Hadley 3 and CCSM 3 and average the period 1900-2000 for each climate variable and county $i\left(\bar{S}_{i}^{1900-2000}\right)$. We correct using the corresponding 100-year average for historical weather $\left(\bar{I}_{i}^{1900-2000}\right)$ from the data described in Section 4.2 as follows:

$$
S_{i, t}^{\text {corrected }}=S_{i, t}^{\text {predicted }}+\left(\bar{S}_{i}^{1900-2000}-\bar{I}_{i}^{1900-2000}\right)
$$

\subsection{Public Opinion Data on Climate Change}

To provide an additional test of our model, we utilize high resolution (county-level) estimates of climate change perceptions from Howe et al. (2015). This dataset contains estimates of climate change perceptions constructed using multiple climate surveys and multilevel regression and poststratification (MRP) techniques. The underlying survey data is taken from twelve nationally representative surveys conducted by the Yale Project on Climate Change Communication and George Mason Center for Climate Change Communication between 2008 and 2013. Because these are modeled beliefs estimated using survey data in combination with demographic and geographic predictors, Howe et al. (2015) perform both internal cross-validation and external validation with independent, sub-national surveys to verify the strength of their approach. MRP techniques in combination with validation have been found to more accurately predict public opinion at disaggregated geographies than other methods (Warshaw and Rodden 2012).

\subsection{Other Predictors of Agricultural Land Value}

We also include soil quality variables in this analysis, specifically measures of susceptibility to floods, soil erosion (K-Factor), slope length, sand content, irrigation, and permeability. The underlying data come from the National Resource Inventory (NRI). The NRI is a largescale survey of soil samples and land characteristics from roughly 800,000 sites in the United States. These variables are calculated as weighted averages across sites used for agriculture, where the weight is the amount of land the sample represents in the county. See Deschênes and Greenstone (2007) and Deschênes and Greenstone (2011) for more details. Finally, we 
follow MNS and include linear and quadratic controls for per capita income and population density in the Ricardian regression.

\subsection{Sample Construction and Summary Statistics}

Our sample consists of all counties located east of the 100th meridian with valid measurement on farmland values in the 2007 Census of Agriculture. We restrict the analysis to counties located east of the 100th meridian following Schlenker, Hanemann, and Fisher (2006) since those counties rely primarily on rainfall as opposed to irrigation like the counties in the American West. Because climate likely has a different effect on urban land prices, and urban land prices can affect agricultural land prices through the potential for development (Plantinga, Lubowski, and Stavins 2002), we follow Schlenker, Hanemann, and Fisher (2005) and exclude counties with a density of more 400 people per square mile or a population greater than 200,000 at any point in our sample. The final sample consists of 2,112 counties. Table 1, Panel 1 reports the average value of land and buildings per acre is $\$ 2,346$ (in 2005 dollars).

Table 1 also reports county-level summary statistics on the climate variables for the 2007 cross-section. Panel 2 shows the average of seasonal average temperature $\left({ }^{\circ} \mathrm{F}\right)$ and total precipitation (inches). The well-known seasonality in average temperature and precipitation is evident, with the summer season being the warmest and wettest. Panel 2 displays the average of the historical climate indices. These entries correspond to Equation (No Change Index) are simply given by the entries in Panel 2 multiplied by the proportionality factor 32.1 , reflecting our choice of a discount rate of $3 \%$ to construct the indices in our primary specifications.

\section{Empirical application}

We now turn to implementing the theoretical asset pricing model to determine whether expectations regarding climate change play a significant role in agricultural land pricing in the United States. To do this, we update the framework of MNS. Hedonic-like estimation methods potentially suffer from many pitfalls, and addressing all of these is beyond the scope of this paper. Instead, we focus on understanding the role expectations of climate change may already be playing in the market. 


\subsection{Empirical specification}

Ideally, we could directly implement an empirical version of Equation (11) in the theoretical model. This model is similar to that of MNS, and includes various other covariates to control for land prices at the county level. The infeasible regression is:

$$
P_{i s}=\alpha+Y_{i}^{\prime} b+X_{i}^{\prime} \xi+\gamma_{s}+\varepsilon_{i s}
$$

where $P_{i s}$ is the observed price per acre of land in county $i$ in state $s$. Other county and land characteristics are included in $X_{i}$. This includes both variables that are potentially exogenous with respect to our measures of climate (such as soil salinity and slope), and variables that may be correlated with land values (such as development pressure and other demand variables). Our preferred specification includes state fixed effects $\left(\gamma_{s}\right)$ to capture statespecific unobserved factors that predict land values (and may be correlated with climate) such as agricultural policy, taxes, uncertainty, etc. Since there is a limited extent of climatic variation within states (both historically and in terms of future climate predictions from GCMs), we also report estimates from models that exclude state fixed effect. In general, both sets of estimates are similar.

Recall that $Y \equiv \sum_{t=0}^{\infty} \mathbb{E}\left[\mathcal{S}_{t}\right] \delta^{t}$. The central issue in implementing the theoretically correct Equation (11) is that while the state space is observable in the form of a collection of climate forecasts, actual market beliefs over the state space are not observable by the econometrician. Thus, we do not observe $Y$. It follows that implementing the regression model underlying Equation (11) requires assuming a model for $Y$ (i.e., a model that describes how expectations about the future state are formed).

\subsection{Testing whether land markets capitalize expectations}

Though the analyst does not directly observe $Y$, data are readily available on current climate as well as for many climate forecasts. These climate forecasts have been developed in part for the IPCC's Assessment Reports, and have been reported by various media markets and discussed extensively by policy makers and scientists. ${ }^{25}$ While individuals may not be directly aware of all this information, the forward-looking market should have capitalized some of the information into the average county prices we observe. Thus, it seems reasonable to

25. In fact, the IPCC has ensured that the results of thousands of climate change simulations performed by seventeen scientific collaborations are available in common format to the general public. 
use these data to develop estimates of climate change beliefs, although alternative data and information sets surely are used by rational market agents.

Instead of taking a firm stance on which forecast best represents mean beliefs, we utilize a flexible parametric model that permits linear mixing of different climate scenarios to choose a 'belief' parameter that weights different scenarios to best match observed prices. To maintain tractability, we select two climate change scenarios: the 'no-change' scenario $\left(S_{0 i}\right.$ represented by historical climate variables that are used in the standard application of the Ricardian method), and the 'stochastic change' scenario $\left(S_{i t}\right.$, represented by the data from either the Hadley 3 or CCSM 3 Scenario A2 models). We assume that markets beliefs are a weighted average of these no-change and stochastic change scenarios. ${ }^{26}$ Specifically, suppose we consider data dated from 2007 to 2099 and let $\hat{Y}_{i}$ be the constructed beliefs for county $i$ :

$$
\begin{aligned}
\hat{Y}_{i}(\pi) & =\sum_{t=2007}^{2099} \pi S_{0 i} \delta^{t-2007}+\sum_{t=2007}^{2099}(1-\pi) S_{i t} \delta^{t-2007} \\
& =\pi I_{i}+(1-\pi) \sum_{t=2007}^{2099} S_{i t} \delta^{t-2007}
\end{aligned}
$$

Thus beliefs are specified up to a scalar parameter $\pi$ that can be estimated jointly with the other parameters of the model (but maintaining an assumed value of $\delta$ ). This structural parameter defines the weighting the market places on each of the two climate change scenarios.

An added advantage of parametrizing beliefs as we have is that it permits testing whether or not land markets are capitalizing expectations. Because the constructed market beliefs above include historical (no change) climate as one of the climate scenarios, the parameter $\pi \in[0,1]$ can be interpreted as the weight the market places on the possibility that climate will not change. If $\pi=1$, then the market places no weight on expectations about the future climate. This is implicitly the assumption made in current applications of the standard Ricardian method. Alternatively, if $\pi<1$, then the market places some weight on expectations, and beliefs about climate change are being capitalized in the land market.

The feasible version of Equation (19) incorporating the parametric model of beliefs is given by:

$$
P_{i s}=\alpha+\hat{Y}_{i}^{\prime}(\pi) b+X_{i}^{\prime} \xi+\gamma_{s}+\varepsilon_{i s}
$$

Since the vector of parameters $b$ and the scalar parameter $\pi$ enter multiplicatively, we esti-

26. We focus on two scenarios, but adding additional scenarios is straightforward. 
mate Equation (21) using non-linear least squares (NLLS) to jointly estimating the $b$ and $\pi$. Since $\pi$ enters Equation (21) linearly, calculation of the marginal effects is not complicated by non-linearities in $\pi$. However, the interpretation of the marginal effects need qualifications:: $b$ captures the effect of marginal changes in market beliefs $\hat{Y}(\pi)$, not of historical climate. Finally, since we interpret $\pi$ as a probability, estimates of $\pi$ that fall outside of the unit interval are problematic for interpretation. Thus for the estimation we use a transformation that ensures all values of $\pi$ lie in the $[0,1]$ interval:

$$
\pi=g(\tilde{\pi})=\frac{1}{1+\exp (\tilde{\pi})}
$$

where $\tilde{\pi}$ can take any value on the real number line.

\section{Empirical Results and Discussion}

We now illustrate the forward-looking Ricardian method empirically by estimating two versions of Equation (21) (each version uses a different climate forecasts to estimate beliefs, $\left.Y_{i}(\pi)\right)$ and presenting the parameter estimates and the predicted climate change damages. We have three specific objectives. First, we test to what extent land markets capitalize expectations about future climate. This amounts to estimating the parameter $\pi$ in Equation (21) and performing the required statistical test. Second, we report the theoretically correct climate-price gradient parameters $b$. Third, we use the empirical estimates of $b$ and $\pi$ to derive the predicted damage of climate change on U.S. agriculture. We also compare the damage estimates obtained from the theoretically correct forward-looking Ricardian method and the 'myopic' versions based on Equations (12) and (13). We then use spatial heterogeneity in perceptions of the likelihood of climate change to determine whether variation in county-level climate change perceptions impact the relationship between climate and the price of agricultural land. Finally, we pool data on land values, climate, and climate expectations over 1987-2007 to estimate how the climate change belief parameter $(\pi)$ has evolved time. Overall, this section illustrates that the proposed forward-looking Ricardian method is empirically relevant and simple to implement with readily available data.

At the same time, we also acknowledge that there are a large number of factors that affect land values, and as such, the cross-sectional regression estimates we report here may still reflect omitted variable bias. ${ }^{27}$ The approach we propose theoretically and empirically

27. Recent research demonstrates that cross-sectional hedonic regressions may produce unreliable estimates 
identifies and addresses a new primary source of bias. It also suggests that commonly used approaches for addressing omitted variables bias (such as including fixed effects) may be insufficient in the case of outcomes of forward-looking markets. Since our empirical model does not control for unobserved land value determinants that may be correlated with climate, we do not claim that the empirical estimates reported in the paper correspond to 'causal' estimates of the climate-price gradients. To minimize concern about spatially correlated omitted variables, some specifications include state fixed effects (Kuminoff, Parmeter, and Pope 2010).

\subsection{Estimates for US agricultural land east of 100th meridian}

Our primary specification utilizes cross-sectional data from the 2007 Agricultural Census for the agricultural counties located east of the 100th meridian. By 2007, the possibility of climate change was plausibly in the information set of farmers and market participants, particularly given the broad media attention given to the topic throughout the early 2000s. Various polls suggest that the American public is concerned about the possibility of climate change (for example, Leiserowitz (2007); Howe et al. (2015)). As such it is reasonable to assume that observed land values reflect expectations about the future climatic conditions associated with each county. Table 2 reports the NLLS regression parameters estimates from Equation (21) along with the estimated standard errors.

Columns (1a) - (1d) correspond to the estimates based on the model the assumed belief equation $Y_{i}(\pi)$ is formed using the Hadley3 A2 climate predictions, and columns (2a) - (2d)

correspond to the case where $Y_{i}(\pi)$ is based on CCSM3 A2. In each case, the (a) and (c) columns report the parameter estimate, and the (b) and (d) columns report the estimated standard error. The (a) and (b) columns are from models that exclude state fixed effects, and the $(\mathrm{c})$ and $(\mathrm{d})$ columns are from models that include them. In each regression, there are 16 climate parameters, corresponding to the average temperature and total precipitation variables, by season, and including a linear and quadratic term. These parameters reflect the marginal effect of a weighted sum of the "No change" index $I_{i}$ and the "Mean forecast" index $Y_{i}$ given by one of two climate models, where the weight $\pi$ is empirically determined by the NLLS regression.

The first row in Table 2 reports the estimate of the parameter $\pi$, the weight assigned by the market to the 'No change' and 'Stochastic change' scenarios. Recall that $\pi$ captures in a variety of settings (Black 1999; Chay and Greenstone 2005; Deschênes and Greenstone 2007). 
the market belief that climate change will not occur; $1-\pi$ represents the market belief that climate change will occur (as represented by either the Hadley or CCSM models). In all specifications the estimated parameter is relatively small (i.e. $0.08-0.22$ ) and is statistically different than both 0 and 1 at conventional levels. The models that include the state fixed effects produce larger estimates of $\pi$. A test of the hypothesis that $\pi=1$ is rejected with a p-value less than 0.001 in all models. Thus it is evident that expectations about the future climate appear to already be priced in the agricultural land markets. Moreover, though the point estimates for $\pi$ from both specifications (1) and (2) are statistically indistinguishable from each other.

The next rows of Table 2 report the climate-price gradient parameters. For each model of belief formation, these correspond to the marginal effect of individual component of $Y_{i}(\pi)$ (the composite index of future climate expectation, in present value term) on land values. The F-statistics reported in the bottom of Table 2 indicate the land market capitalizes the information about future climate that is contained in our composite index $Y_{i}(\pi)$. These test the joint significance of the 16 climate index variables that are included in the NLLS regressions. In the case of beliefs based on Hadley 3 (1a), the F-statistics are 28.89 and 11.90, while for beliefs based on CCSM 3 (2a), the F-statistics are 20.01 and 6.36. In all cases the p-values associated with these tests are 0.001 or less. Examination of the coefficients reveals that the inclusion of the state fixed effects tends to reduce the (absolute) magnitude of the estimated temperature and precipitation coefficients. The estimated coefficients further illustrate that farmland values are sensitive to beliefs, but not to the particular forecast used to estimate beliefs. In particular, comparison of the coefficients in (1a) and (2a), and (1c) and (2c) reveals marginal effects that are generally of same sign and similar magnitude across the two models of belief formation. It is also notable that the inclusion of the state fixed effects, while reducing the magnitude of the estimated coefficients, does not generally alter the statistical significance: most of the statistically significant coefficients in columns (1a) and (2a) remain significant in columns (1c) and (2c). Given this, we now focus on the specification with state fixed effects as it appears well identified in the data, and provides better control against omitted variables bias.

Table 3 reports the total present value of the climate change impacts as well as the corresponding annualized impacts. The annualized impacts are calculated by scaling the total present value impacts by the proportionality factor implied by the discount rate of $3 \%$. The annualized impact is interpreted as the average yearly impact of climate change over the period 2007-2099, while the total present value is simply the cumulative sum of the impacts 
over 2007-2099, discounted to 2007. We report estimates corresponding to three different models of beliefs about future climate change: beliefs given by the weighted sum of the 'No change' index $I_{i}$ and the Hadley3 A2 'Mean forecast' index $Y_{i}$ (with weight corresponding to the empirical estimate of $\pi$ in (1a)), beliefs given by the weighted sum of the 'No change' index $I_{i}$ and the CCSM3 A2 'Mean forecast' index $Y_{i}$ (with weight corresponding to the empirical estimate of $\pi$ in (2a)), and beliefs based only on the 'No change' index $I_{i}$. This final set of beliefs corresponds to the approach taken in all previous applications of the Ricardian method that implicitly assume $\pi=1$. The total present value of the change in farmland values associated with climate change across all counties is given by the application of Equations (18) and (20) to a specific model for belief formation, and the related empirical estimate of $\pi$, denoted by $\hat{Y}_{i}(\hat{\pi})$ :

$$
\sum_{i}\left(\hat{Y}_{i}(\hat{\pi})-I_{i}\right)^{\prime} \hat{b}=(1-\hat{\pi}) \sum_{i}\left(Y_{i}^{\mathrm{Had} 3 \mathrm{~A} 2 \text { or CCSM3A2 }}-I_{i}\right)^{\prime} \hat{b}
$$

Table 3 indicates that if beliefs are estimated using the Hadley 3 forecast and this model indeed describes how climate indeed evolves, the total present value damage of climate change is $\$ 998.6$ billion over the next century, annualized to $\$ 31.1$ billion (column (1), rows 1 and 3). On the other hand, if beliefs are estimated with the CCSM 3 forecast and the future climate path follows CCSM 3, the predicted total present value damage of climate change is almost the same at $\$ 968.0$ billion (column (2), rows 2 and 4 ). These estimates, like all others reported in Table 3, are statistically significant at the conventional level. The other predicted impacts in columns (1) and (2) correspond to the case where beliefs are modeled on one climate model, but the realized future climate path evolves according to the other. These estimates are qualitatively similar to the others.

By comparison, estimates of the present value of damages up to 2099 from the application of myopic Ricardian approach (the 'No change' index in column 3) range from $\$ 600.2$ to $\$ 711.1$ billion. The standard Ricardian estimates of the impact of climate change that ignore the fact that the land market capitalizes expectations about future climate understate damages by $36 \%$ to $66 \%$, depending on the specifics of the model. ${ }^{28}$ Notably, all estimates in Table 3 are negative (indicating net losses from climate change) and are relatively large (the entire value of US agricultural farmland, buildings, and holdings in 2007 was $\$ 1.74$ trillion, while total production and payments to the agricultural sector was about $\$ 297$ billion in

28. Comparing the results for the Hadley path formed under Hadley beliefs with those of the No Change model, the estimated impacts are $1-(998 / 600)=66 \%$. 
2007). ${ }^{29}$ The bias demonstrated in the theoretical section is economically important: In dollar terms, the bias in the myopic Ricardian model (i.e. comparing column (3) to (2) and (1)) is large and corresponds to as much as $22 \%$ of total US agricultural farmland, buildings, and holdings in $2007 .^{30}$

Given the estimates from Table 2, we can estimate any number of climate paths (rows in Table 3). To illustrate, the diagonal elements of Table 3 assume that beliefs are modeled on the true (mean) path climate will take, whereas the off-diagonal assume the alternatives are realized. It is encouraging that two correct-belief estimates (in the diagonals of Table 3) are very similar in magnitude, indicating that the flexibility given by letting $\pi$ vary empirically works as expected.

\subsection{Varying the discount rate}

The empirical implementation of the forward-looking Ricardian model requires an assumption about the discount rate. In the preceding analysis, we have assumed a discount rate of $3 \%$ to reflect the long run nature of rural land investments. For policy analysis relating to climate change or other multi-generational phenomena, economic arguments justify using discount rates that more closely equate distant future and near term time horizons (Weitzman 1998). In this case $3 \%$ may be too large or small, so we estimate damages over a range

of discount values from $[0.5 \%, 6.5 \%]$. This covers a wide range of horizons. For example, a constant revenue stream reaches $95 \%$ of its discounted value after 98 years with a discount rate of $3 \%$, while this takes 297 years with a discount rate of $1 \%$ and 58 years with a discount rate of $5 \%$.

Figure 1 shows the estimated market beliefs and climate change impacts associated with a wide range of discount rates. As in the prior analysis, these results are shown for beliefs constructed from the Hadley 3 and CCSM 3 data. The estimated parameters corresponding to the market belief on the 'No change' scenario $(\pi)$ are obtained from estimating versions of Equation (19) that are constructed using the different assumptions on the discount rate (in order to form $Y(\pi)$ ) and that include state fixed effects and all the other control variables. Overall, we find that the estimated market belief parameters are similar for the range of discount rates we consider. For the beliefs constructed using the Hadley 3 data the estimates of $\pi$ range from 0.17 to 0.21 , while for the beliefs constructed using the CCSM 3 data, the estimates of $\pi$ range from 0.20 to 0.22 . Thus it is evident that these results are not driven

29. These values are from the 2007 US Census of Agriculture.

30 . That is, $(998-600) / 1740=22 \%$. 
to a first order by the choice made on the discount rate.

Figure 2 graphically reports the estimated climate change impacts associated with the various discount rates. These are obtained from the same regressions underlying Figure 1. The entries are in billions of 2005 dollars. Several noticeable patterns emerge from Figure 2. As expected, it is evident that predicted damages are larger when the discount rates are smaller. For example, the damages associated with a discount rate of $1 \%$ are around negative $\$ 1100$ billion for both sets of constructed beliefs. A discount rate of 3\% returns the same damage estimates as those reported in Table 3 (-\$998.6 for Hadley and $-\$ 968.0$ for CCSM). For larger discount rates, the gap between the Hadley-based and CCSM-based damages grows: for example when the discount rate is $6.5 \%$, the Hadley damage is $57 \%$ larger than the CCSM-based damage.

\subsection{Heterogeneity in climate change beliefs}

There is substantial heterogeneity in the degree to which different economic agents assess the likelihood of climate change. Even among rural farmers in the US Midwest, there is variation in opinions over the likelihood of severe climate change and its causes (Arbuckle et al. 2013). Such differences could confound our estimates if beliefs are correlated with the mean path of climate evolution. The existence of heterogeneity also suggest an additional test of our hypothesis that land markets capitalize future climate expectations: land values in counties where climate change is thought to be more likely should reflect future climate forecasts more strongly than in counties where beliefs over the likelihood of climate are weaker.

To this end, we again estimate Equation (21), but now incorporate the estimated percentage of each county's population who think that 'global warming is happening' (Howe et al. 2015 terminology). ${ }^{31}$ We incorporate this variable in two ways. First, we include it as a linear predictor of land values in the vector $X$. This provides a simple test of whether climate change perceptions are correlated with land prices. Second, we allow the parameter $\pi$ to vary across counties as a function of the local level of belief in climate change. This amounts to interacting beliefs with climate levels:

$$
\pi_{i}=\frac{1}{1+\exp \left(\theta_{0}+\theta_{1} S C C H_{i}\right)}
$$

where $S C C H_{i}$ denotes the share of each county's population who think that global warming

31. The variable 'happening' in Howe et al. (2015). 
is happening, taken from the Howe et al. (2015) data. If $\theta_{1}$ is positive, then higher local perceived likelihood of climate change is associated with a lower value of the parameter $\pi$ and higher weighting on future climate, supporting our hypothesis.

Results from this analysis are shown in Table 4. All models include state fixed effects. Columns (1) and (4) reproduce columns (1c) and (2c) in Table 2 and restrict the market belief parameter $\pi$ to be same across all counties. Columns (2) and (5) maintain this restriction, but introduce the county-specific climate change perception ( $\mathrm{SCCH}$ ) as an additional predictor of land values. In both specifications, the coefficient on the share of population 'believing climate change is happening' is positive but statistically insignificant. The estimated market belief parameter $\pi$ are essentially the same as in the baseline specification of columns (1) and (4). In columns (3) and (6) we consider specifications where local perceptions of the likelihood of climate change can affect the market belief parameter, as in

the above equation. Specifically, we estimate the parameters $\theta_{0}$ and $\theta_{1}$ (in addition to the climate price gradient parameter vector $b$ ), and then construct predicted market beliefs as a function of SCCH (share of population 'believing climate change is happening'). These predicted values (and standard errors) are reported in the lower panel of Table 4 for low $(\mathrm{SCCH}=45)$, mean $(\mathrm{SCCH}=57.7)$, and high $(\mathrm{SCCH}=76)$ perceptions of the likelihood that climate change is happening. In both the (3) and (6) specifications, there is a clear inverse relationship between the predicted market belief parameter $\pi$ and the county-level perception of climate change. Counties where climate change is perceived as a low likelihood $(\mathrm{SCCH}=45)$ have estimates of $\pi$ in the $0.36-0.37$ range, while counties where climate change is perceived as a high likelihood $(\mathrm{SCCH}=76)$ have estimates of $\pi$ in the 0.06-0.08 range (and statistically indistinguishable from 0 ). This evidence suggest that land values in counties with higher population shares believing that climate change is happening are priced with a higher weight on future climate expectations (represented empirically by the Hadley 3 and CCSM 3 predictions) as opposed to the historical climate.

\subsection{Evolution of climate change beliefs over time}

Using data on land values, county agricultural characteristics, and climate indices from prior years, we explore the evolution of the market belief parameter over time. This approach provides a simple specification test of the assumptions of our model and its empirical credibility. Naturally, we should expect that the market belief for the 'No change' scenario $(\pi)$ grows larger as it is estimated from older data when public information on the prospects of 
climate change was not as widespread. In other words, we expect the estimate of $\pi$ for 2007 to be smaller than the corresponding estimate for 1987 (reflecting a stronger market belief in the likelihood of climate change in 2007 than in 1987).

Specifically, we estimate an augmented version of regression Equation (21), but pool the data from 1987 to 2007 and include year fixed effects. The market belief parameter $\pi$ is permitted to vary over time; all other parameters are restricted to be the same across periods (with the exception of year fixed effects). The constructed climate belief index $Y(\pi)$ are constructed in the same manner as Equation (20), with the exception that indices for earlier periods are discounted back to the relevant year (e.g., the indices for 1987 are discounted to 1987).

Table 4 reports the coefficient estimates for the market belief parameters, when beliefs are constructed from the Hadley (columns 1a and 1b) and CCSM (columns 2a and 2b) data. The F-statistics at the bottom of the table test the equality of the market belief parameters over the period 1987-2007. For both sets of constructed beliefs, the hypothesis of equality is rejected by the data at the $1 \%$ level or better. It is also evident that the patterns in the estimated parameters correspond to our intuition regarding the salience and public knowledge about ongoing climate change. In earlier years, $\pi$ is larger, and as time moves forward, $\pi$ decreases as the market incorporates the greater threat and likelihood of climate change. Overall, this simple test supports our working hypothesis about the land market incorporating more information over time about expected future climate change in pricing agricultural land.

\section{Conclusion}

A fundamental underpinning of capital asset theory is that anticipated changes in future benefits associated with an asset will be capitalized into its current price. This key insight is routinely applied in hedonic regressions designed to value non-market attributes in order to assess the impact of expected future changes. For example, climate can affect agricultural land values, zoning regulations can affect housing markets, and financial or workplace regulations can affect a company's valuation.

The canonical application uses historical data to estimate the response of asset prices to exogenous variation in a variable of interest that is expected to change in the future. Given an empirical estimate of the relationship between asset values and the variable of interest, it is straightforward to predict the costs or benefits associated with expected future 
changes in this variable. This approach has been applied across numerous economic assets in many sectors, and reported in hundreds of papers. The primary purpose of this paper is to show that the empirical component of this approach to economic valuation contains a fundamental assumption that is unlikely to hold in today's information-rich society. The implicit assumption is that the market is completely ignorant of the future change that is now anticipated by the analyst. We propose and test a straightforward correction that allows current asset markets to capitalize future expectations.

In climate change applications, scientists often predict increasing temperatures and changing precipitation patterns, but all empirical applications of the Ricardian method in the literature implicitly assume that current land markets ignore these predictions. While this assumption was quite plausible in the 80's and 90's, it is reasonable to wonder whether land markets are starting to account for publicly available climate forecasts. Ignoring this possibility leads to bias in the standard Ricardian regression. We derive the direction and magnitude of the bias, and show how it can be corrected. The direction and magnitude of the bias turns out to hinge on the correlation between past and future states and on the variances of those states. The bias can be positive, negative, or (in very special cases) zero.

Indeed, we find clear evidence that current agricultural land markets do capitalize expectations about future climate: Future climate indices derived from climate predictions from the Hadley 3 and CCSM 3 global circulation models are shown to be important predictors of current land values, conditional on historical climate indices, state fixed effects, soil characteristics, and other predictors of farmland values typically used in standard application of the Ricardian method. Thus, while the theoretical points we derive here are relevant whether or not current markets actually capitalize future climate, we have also shown that this effect may already be unfolding across the United States. Our simple empirical illustration indeed suggests that ignoring the capitalization of future climate expectations in the Ricardian method may lead us to underestimate damage by $36 \%$ to $66 \%$. Future research should continue to investigate this important question as more detailed and refined information on farmers' and markets' information sets and expectations become available. 


\section{References}

Albouy, David, et al. 2016. Climate Amenities, Climate Change, and American Quality of Life. Journal of the Association of Environmental and Resource Economists 3 (1): 205 -246 .

Arbuckle, J Gordon, et al. 2013. Climate change beliefs, concerns, and attitudes toward adaptation and mitigation among farmers in the Midwestern United States. Climatic Change 117 (4): 943-950.

Auffhammer, M, et al. 2013. Using Weather Data and Climate Model Output in Economic Analyses of Climate Change. Review of Environmental Economics and Policy 7 (2): $181-198$.

Bayer, Patrick, et al. 2016. A dynamic model of demand for houses and neighborhoods. Econometrica 84 (3): 893-942.

Bishop, Kelly C. 2015. A Dynamic Model of Location Choice and Hedonic Valuation.

Bishop, Kelly C, and Alvin D Murphy. 2011. Estimating the Willingness to Pay to Avoid Violent Crime: A Dynamic Approach. The American Economic Review 101 (3): 625629.

Black, Sandra E. 1999. Do better schools matter? parental valuation of elementary education. Quarterly journal of economics:577-599.

Blomquist, G C, M C Berger, and J P Hoehn. 1988. New estimates of quality of life in urban areas. The American Economic Review:89-107.

Burke, M, and K Emerick. 2013. Adaptation to Climate Change: Evidence from US Agriculture.

Chang, Ching Cheng. 2002. The potential impact of climate change on Taiwan's agriculture. Agricultural Economics 27 (1): 51-64.

Chay, Kenneth Y, and Michael Greenstone. 2005. Does air quality matter? evidence from the housing market. Journal of political economy 113 (2): 376-424.

2007. Climate change 200\%: Synthesis report. Technical report. Intergovernmental Panel on Climate Change.

Cragg, M, and M Kahn. 1997. New estimates of climate demand: evidence from location choice. Journal of Urban Economics 42 (2): 261-284.

Davis, Lucas W. 2004. The effect of health risk on housing values: Evidence from a cancer cluster. The American Economic Review 94 (5): 1693-1704.

Deryugina, Tatyana. 2013. How do people update? The effects of local weather fluctuations on beliefs about global warming. Climatic Change:1-20. 
Deschênes, Olivier, and Michael Greenstone. 2007. The Economic Impacts of Climate Change: Evidence from Agricultural Output and Random Fluctuations in Weather. The American Economic Review 97 (1): 354-385.

. 2011. Climate Change, Mortality, and Adaptation: Evidence from Annual Fluctuations in Weather in the US. American Economic Journal: Applied Economics 3 (4): $152-185$.

. 2012. The economic impacts of climate change: evidence from agricultural output and random fluctuations in weather: reply. American Economic Review 102 (7): 376173 .

Gallagher, Justin. 2014. Learning about an infrequent event: evidence from flood insurance take-up in the united states. American Economic Journal: Applied Economics 6 (3): $206-233$.

Hornbeck, R, and P Keskin. 2014. The Historically Evolving Impact of the Ogallala Aquifer: Agricultural Adaptation to Groundwater and Drought. American Economic Journal: Applied Economics 6 (1): 190-219.

Howe, Peter D, et al. 2015. Geographic variation in opinions on climate change at state and local scales in the usa. Nature Climate Change 5 (6): 596-603.

Kelly, David L, Charles D Kolstad, and Glenn T Mitchell. 2005. Adjustment costs from environmental change. Journal of Environmental Economics and Management 50 (3): 468-495.

Kennan, John, and James R Walker. 2011. The effect of expected income on individual migration decisions. Econometrica 79 (1): 211-251.

Kuminoff, Nicolai V, Christopher F Parmeter, and Jaren C Pope. 2010. Which hedonic models can we trust to recover the marginal willingness to pay for environmental amenities? Journal of Environmental Economics and Management 60 (3): 145-160.

Kurukulasuriya, Pradeep, et al. 2006. Will African agriculture survive climate change? The World Bank Economic Review 20 (3): 367-388.

Leiserowitz, Anthony. 2007. International Public Opinion, Perception, and Understanding of Global Climate Change. Technical report.

Linden, Leigh, and Jonah E Rockoff. 2008. Estimates of the impact of crime risk on property values from megan's laws. The American Economic Review:1103-1127.

Liu, Hui, et al. 2004. Study on the impacts of climate change on China's agriculture. Climatic Change 65 (1-2): 125-148.

Madison, D. 2000. A hedonic analysis of agricultural land prices in England and Wales. European Review of Agricultural Economics 27 (4): 510-532. 
Massetti, E, and R Mendelsohn. 2011. Estimating Ricardian models with panel data. Climate Change Economics 02 (04): 301-319.

Mendelsohn, R, W D Nordhaus, and D Shaw. 1994. The impact of global warming on agriculture: a Ricardian analysis. The American Economic Review:753-771.

Mendelsohn, Robert, William Nordhaus, and Daigee Shaw. 1996. Climate impacts on aggregate farm value: accounting for adaptation. Agricultural and Forest Meteorology 80 (1): $55-66$.

Meng, Kyle. 2013. The Cost of Potential Cap-and-Trade Policy: An Event Study using Prediction Markets and Lobbying Records.

Nickerson, Cynthia, and Wendong Zhang. 2014. Modeling the determinants of farmland values in the united states. Chap. 5 in The oxford handbook of land economics, ed. Joshua M. Duke and JunJie Wu, 111-138. Oxford: Oxford University Press.

Plantinga, Andrew J, Ruben N Lubowski, and Robert N Stavins. 2002. The Effects of Potential Land Development on Agricultural Land Prices. Journal of Urban Economics 52:561-581.

Reidsma, Pytrik, Frank Ewert, and Alfons Oude Lansink. 2007. Analysis of farm performance in Europe under different climatic and management conditions to improve understanding of adaptive capacity. Climatic Change 84 (3-4): 403-422.

Ricardo, David. 1821. On the Principles of Political Economy and Taxation. John Murray.

Roback, J. 1982. Wages, rents, and the quality of life. Journal of Political Economy:12571278.

Rosen, Sherwin. 1974. Hedonic prices and implicit markets: product differentiation in pure competition. The journal of political economy 82 (1): 34-55.

Schlenker, Wolfram, W Michael Hanemann, and Anthony C Fisher. 2005. Will US agriculture really benefit from global warming? Accounting for irrigation in the hedonic approach. The American Economic Review 95 (1): 395-406.

- 2006. The Impact of Global Warming on U.S. Agriculture: An Econometric Analysis of Optimal Growing Conditions. Review of Economics and Statistics 88 (1): 113-125.

Seo, S Niggol, and Robert Mendelsohn. 2008a. An analysis of crop choice: Adapting to climate change in South American farms. Ecological Economics 67 (1): 109-116.

- 2008b. Measuring impacts and adaptations to climate change: a structural Ricardian model of African livestock management1. Agricultural Economics 38 (2): 151-165.

Seo, S Niggol, Robert Mendelsohn, and M Munasinghe. 2005. Climate change and agriculture in Sri Lanka: a Ricardian valuation. Environment and Development Economics 10 (5): $581-596$. 
Sinha, P, and M L Cropper. 2013. The Value of Climate Amenities.

Warshaw, Christopher, and Jonathan Rodden. 2012. How should we measure district-level public opinion on individual issues? The Journal of Politics 74 (01): 203-219.

Weitzman, M L. 1998. Why the far-distant future should be discounted at its lowest possible rate. Journal of Environmental Economics and Management 36 (3): 201-208. 


\section{Appendix I: Excluded counties and county equivalents}

The inverse distance weighting method used to translate gridded climate data from Hadley 3 and CCSM 3 to county centroid data experienced minor issues in some counties at the geographic edge of our sample in Michigan and Florida. Independent cities (which are county equivalents) in Virginia are also excluded; these are typically smaller in land area and urbanized. Weighting failed to produce estimates for one county in Missouri. By state, these counties and county equivalents are:

FLORIDA: Miami-Dade, Monroe.

MICHIGAN: Alcona, Alpena, Charlevoix, Cheboygan, Chippewa, Emmet, Keneenaw, Luce, Mackinac, Montmorency, Ostego, Preqsue, Sanilac, Schoolcraft.

MISSOURI: Ste. Genevieve.

VIRGINIA: Albemarle, Alleghany, August, Bedford, Campbell, Carroll, Dinwiddie, Fairfax, Frederick, Greensville, Henry, Montgomery, Pittsylvania, Prince George, Prince William, Roanoke, Rockbridge, Rockingham, Southampton, Spotsylvania, Washington, Wise. 
Figure 1: Estimated Market Belief Parameters in Climate Not Changing $(\pi)$ as a Function of the Discount Rate

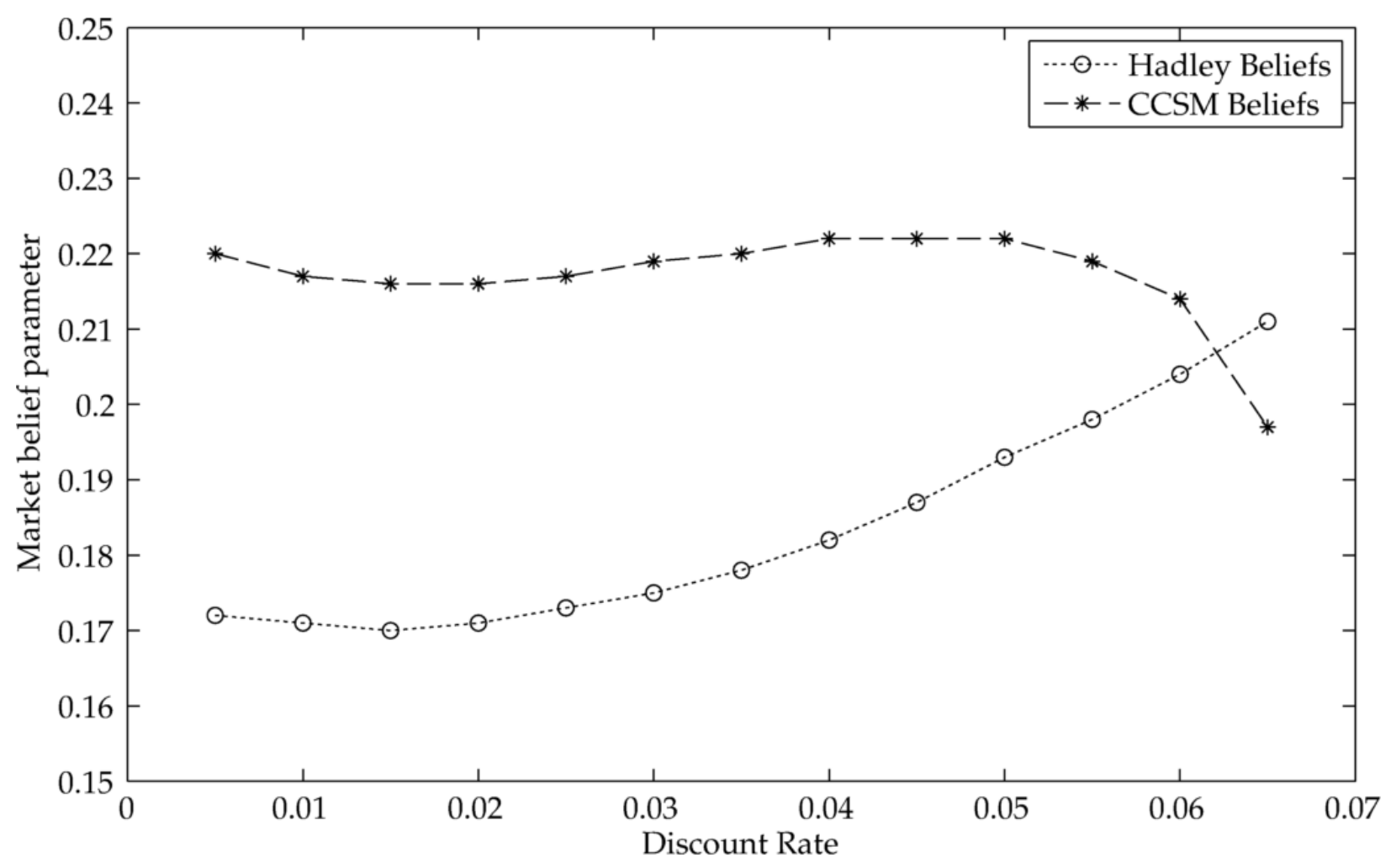


Figure 2: Estimated Present Discounted Value of Estimated Climate Change Impacts as a Function of the Discount Rate

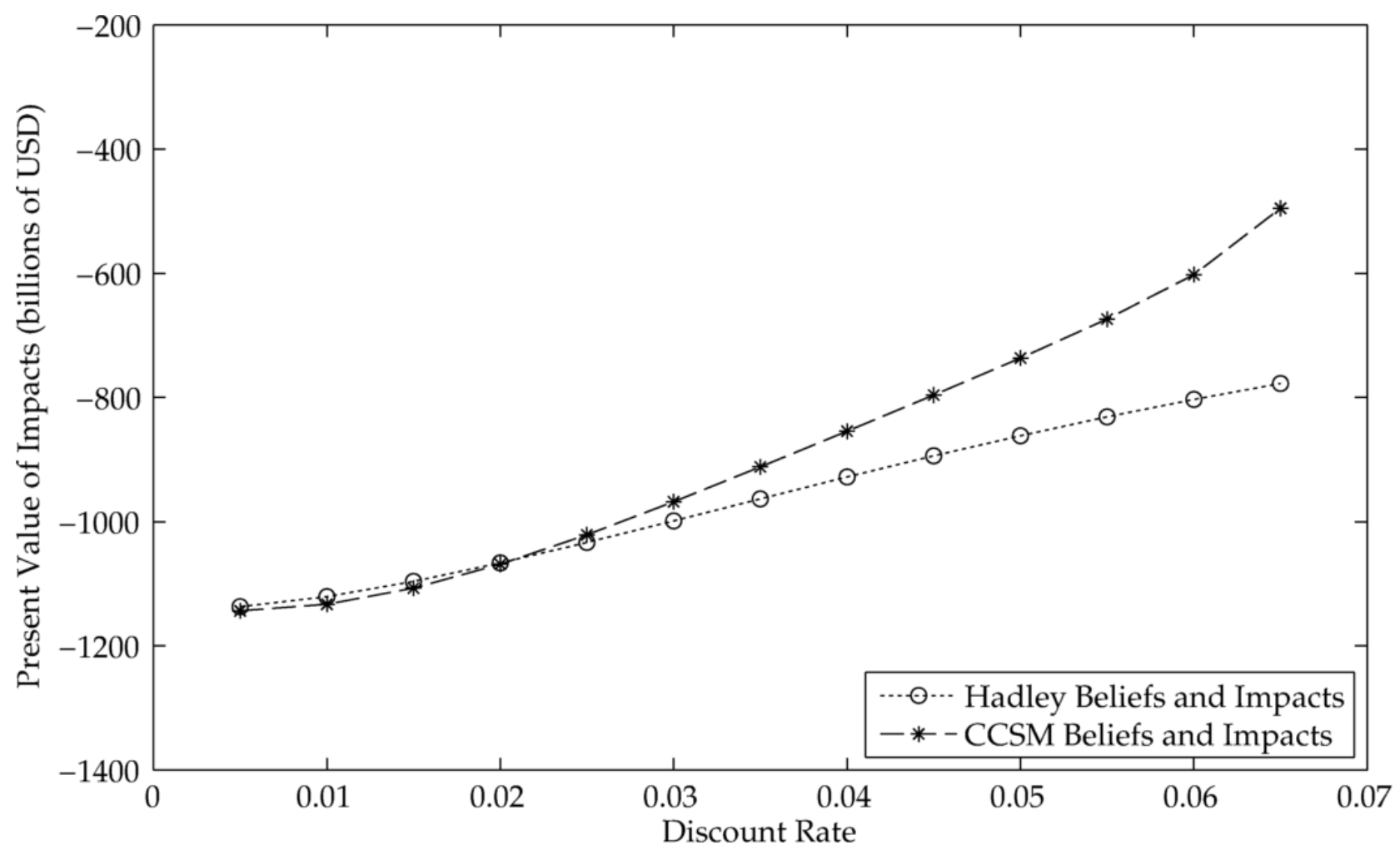


Table 1: Summary Statistics on Historical Climate Variables

\begin{tabular}{|c|c|c|c|c|}
\hline & Mean & Std Dev & Minimum & Maximum \\
\hline 1. Average Farmland Value Per Acre & $2,346.0$ & $1,254.5$ & 449.4 & $20,173.7$ \\
\hline \multicolumn{5}{|l|}{ 2. Historical Climate Variables } \\
\hline Winter Temperature & 33.0 & 12.0 & 7.4 & 65.4 \\
\hline Spring Temperature & 54.7 & 8.2 & 38.3 & 75.0 \\
\hline Summer Temperature & 75.3 & 5.0 & 63.1 & 86.3 \\
\hline Fall Temperature & 56.4 & 7.9 & 39.9 & 76.8 \\
\hline $\begin{array}{l}\text { Winter Precipitation } \\
\text { Spring Precipitation }\end{array}$ & $\begin{array}{l}2.1 \\
3.5\end{array}$ & $\begin{array}{l}1.4 \\
0.9\end{array}$ & $\begin{array}{l}0.4 \\
1.4\end{array}$ & $\begin{array}{l}5.7 \\
5.7\end{array}$ \\
\hline Summer Precipitation & 3.8 & 0.8 & 2.1 & 8.2 \\
\hline Fall Precipitation & 3.0 & 0.9 & 1.2 & 6.0 \\
\hline \multicolumn{5}{|l|}{ 3. Discounted Historical Climate Indices } \\
\hline Winter Temperature & $1,059.3$ & 385.7 & 239.4 & $2,100.2$ \\
\hline Spring Temperature & $1,756.3$ & 262.0 & $1,230.5$ & $2,410.1$ \\
\hline Summer Temperature & $2,420.8$ & 161.1 & $2,026.2$ & $2,773.2$ \\
\hline Fall Temperature & $1,813.9$ & 252.7 & $1,281.1$ & $2,468.2$ \\
\hline Winter Precipitation & 69.0 & 45.2 & 13.5 & 183.4 \\
\hline Spring Precipitation & 111.3 & 30.1 & 44.8 & 183.9 \\
\hline Summer Precipitation & 122.0 & 24.3 & 66.9 & 264.9 \\
\hline Fall Precipitation & 97.1 & 29.0 & 38.0 & 193.8 \\
\hline
\end{tabular}

Notes: Sample means and standard deviations for 2,112 counties in main estimation sample (counties east of 100th meridian) in 2007. Discounted indices based on 3\% discount rate. See the text for more details. 
Table 2: Estimated Marginal Effects from Forward-Looking Ricardian Regressions, 2007 Cross-Section

\begin{tabular}{|c|c|c|c|c|c|c|c|c|}
\hline \multirow[b]{2}{*}{ Parameter } & \multicolumn{4}{|c|}{ Beliefs based on Hadley 3 A2 } & \multicolumn{4}{|c|}{ Beliefs based on CCSM 3 A2 } \\
\hline & (1a) & (1b) & (1c) & (1d) & (2a) & $(2 b)$ & (2c) & $(2 d)$ \\
\hline$\pi$ & $0.08^{*}$ & $(0.04)$ & $0.18^{*}$ & $(0.08)$ & $0.17^{*}$ & $(0.07)$ & $0.22 * *$ & $(0.08)$ \\
\hline Linear winter temperature index & $-25.67 *$ & $(12.25)$ & -17.50 & $(12.81)$ & $-39.30 *$ & $(14.84)$ & -19.16 & $(10.82)$ \\
\hline Linear spring temperature index & 71.20 & $(37.32)$ & -8.02 & $(21.35)$ & $87.82 *$ & $(41.60)$ & 5.99 & $(22.75)$ \\
\hline Linear summer temperature index & 2.03 & $(66.11)$ & 44.83 & $(55.05)$ & -52.50 & (46.09) & -8.48 & (44.17) \\
\hline Linear fall temperature index & 40.35 & $(67.16)$ & 78.29 & $(59.26)$ & 116.64 & (89.53) & 94.24 & $(58.46)$ \\
\hline Linear winter precipitation index & $-327.06 * *$ & (104.97) & $-196.20 * *$ & $(58.02)$ & -163.61 & $(81.60)$ & $-175.52^{* *}$ & $(63.87)$ \\
\hline Linear spring precipitation index & 49.14 & $(35.50)$ & 41.63 & $(36.43)$ & 25.97 & $(30.22)$ & 30.00 & (31.57) \\
\hline Linear summer precipitation index & $-117.33^{* * *}$ & (31.99) & $-82.44 * * *$ & $(20.41)$ & $-129.88 * * *$ & $(33.87)$ & $-69.01 * * *$ & (19.70) \\
\hline Linear fall precipitation index & $351.60^{* * *}$ & $(72.88)$ & $216.20^{* * *}$ & $(56.92)$ & $215.15^{*}$ & $(79.15)$ & $191.56^{* * *}$ & $(55.44)$ \\
\hline Quad winter temperature index & $0.37^{*}$ & $(0.17)$ & 0.26 & $(0.19)$ & $0.42^{*}$ & $(0.20)$ & 0.27 & $(0.17)$ \\
\hline Quad spring temperature index & $-0.74 *$ & $(0.32)$ & 0.00 & $(0.17)$ & $-0.72^{*}$ & $(0.35)$ & -0.09 & $(0.18)$ \\
\hline Quad summer temperature index & -0.08 & (0.39) & -0.31 & $(0.34)$ & 0.18 & $(0.29)$ & 0.01 & $(0.28)$ \\
\hline Quad fall temperature index & -0.23 & $(0.56)$ & -0.65 & $(0.51)$ & -0.78 & $(0.73)$ & -0.76 & $(0.49)$ \\
\hline Quad winter precipitation index & $34.45^{*}$ & $(14.27)$ & $25.23 * *$ & $(8.92)$ & $28.02^{* *}$ & $(9.62)$ & $24.57^{* * *}$ & $(6.82)$ \\
\hline Quad spring precipitation index & -3.93 & (3.86) & -3.32 & $(4.22)$ & -3.34 & $(3.54)$ & -2.07 & (3.48) \\
\hline Quad summer precipitation index & $11.18^{* *}$ & (3.59) & $8.11^{* * *}$ & $(2.10)$ & $11.30^{* *}$ & $(3.61)$ & $6.08 * *$ & $(2.01)$ \\
\hline Quad fall precipitation index & $-33.81^{* * *}$ & $(7.97)$ & $-24.50 * *$ & $(7.28)$ & $-29.20 * *$ & $(9.71)$ & $-23.97^{* * *}$ & $(6.27)$ \\
\hline F-statistic on 16 indices & 28.89 & & 11.90 & & 20.01 & & 6.36 & \\
\hline [p-value] & {$[0.001]$} & & {$[0.001]$} & & {$[0.001]$} & & {$[0.001]$} & \\
\hline State Fixed Effects & No & No & Yes & Yes & No & No & Yes & Yes \\
\hline
\end{tabular}

Notes: Dollar figures in 2005 constant dollars. All entries are from farmland value regressions on quadratics in eight constructed future climate expectation index (equation 18). Standard errors are clustered on state. Asterisks denote p-value $<0.05(*),<0.01(* *)$, $<0.001(* * *)$. See the text for more details on the other control variables included in the regressions. 
Table 3: Estimated Impacts of Climate Change, Main Estimation Sample, Discounted to 2007, Billions of 2005 Dollars

\begin{tabular}{cc} 
Model of Beliefs & \\
\hline Composite index & Composite index \\
based on Hadley3 A2 $\left(Y_{i}(\pi)\right)$ & based on $\operatorname{CCSM3~A2~}\left(Y_{i}(\pi)\right) \quad$ No Change index $\left(I_{i}\right)$
\end{tabular}

Present Value of Climate Change Impacts

Hadley 3

$\operatorname{CCSM} 3$

$-1,290.7^{* * *}$

$-968.0^{* *}$

(363.2)

$-711.1^{* *}$

(234.9)

\section{Annualized Value of Climate Change Impacts}

Hadley 3

$-31.1^{* * *}$

$-40.2^{* * *}$
$-24.4^{* * *}$

$-21.7^{* * *}$
$-18.7^{* * *}$

$-24.0^{* *}$

Notes: The estimated impacts of climate change are derived from the state fixed effects regressions summarized in Table 2, with corresponding column numbers, i.e., columns (1) and (2) in Table 3 correspond to columns (1c) and (2c) in Table 2. The future climate expectation indices underlying the regressions are constructed with a discount rate of $3 \%$ and so implicitly the reported impacts are discounted assuming a $3 \%$ discount rate. Standard errors in parentheses are linear combination of regression standard errors clustered by state. Asterisks denote $\mathrm{p}$-value $<0.05(*),<0.01(* *),<0.001(* * *)$. 


\begin{tabular}{|c|c|c|c|c|c|c|}
\hline & \multicolumn{3}{|c|}{ Beliefs based on Hadley $3 \mathrm{~A} 2$} & \multicolumn{3}{|c|}{ Beliefs based on CCSM3 A2 } \\
\hline & (1) & (2) & (3) & (4) & (5) & (6) \\
\hline $\begin{array}{l}\text { Share believing climate change } \\
\text { is happening ( } \mathrm{SCCH})\end{array}$ & --- & $\begin{array}{l}10.68 \\
(7.17)\end{array}$ & $\begin{array}{l}37.86^{*} \\
(14.47)\end{array}$ & --- & $\begin{array}{l}13.71 \\
(7.56)\end{array}$ & $\begin{array}{l}41.59^{* *} \\
(13.20)\end{array}$ \\
\hline Market belief parameter $(\pi)$ & $\begin{array}{l}0.18^{*} \\
(0.08)\end{array}$ & $\begin{array}{l}0.18^{*} \\
(0.08)\end{array}$ & --- & $\begin{array}{l}0.22^{* *} \\
(0.08)\end{array}$ & $\begin{array}{l}0.21^{* *} \\
(0.08)\end{array}$ & --- \\
\hline \multicolumn{7}{|l|}{ Predicted $\pi$ as function of SCCH } \\
\hline low $\mathrm{SCHH}(\mathrm{SCHH}=45)$ & --- & --- & $\begin{array}{c}0.37 * * * \\
(0.10)\end{array}$ & --- & --- & $\begin{array}{l}0.36^{* * *} \\
(0.104)\end{array}$ \\
\hline mean $\mathrm{SCHH}(\mathrm{SCHH}=57.7)$ & --- & --- & $\begin{array}{c}0.18^{*} \\
(0.088)\end{array}$ & --- & --- & $\begin{array}{l}0.21^{* *} \\
(0.07)\end{array}$ \\
\hline highest $\mathrm{SCHH}(\mathrm{SCHH}=76)$ & --- & --- & $\begin{array}{c}0.06 \\
(0.05)\end{array}$ & --- & --- & $\begin{array}{c}0.08 \\
(0.05)\end{array}$ \\
\hline $\begin{array}{l}\text { F-statistic on } 16 \text { indices } \\
\text { [p-value] }\end{array}$ & $\begin{array}{c}11.90 \\
{[0.001]}\end{array}$ & $\begin{array}{c}11.82 \\
{[0.001]}\end{array}$ & $\begin{array}{c}14.33 \\
{[0.001]}\end{array}$ & $\begin{array}{c}6.36 \\
{[0.001]}\end{array}$ & $\begin{array}{c}6.69 \\
{[0.001]}\end{array}$ & $\begin{array}{c}6.82 \\
{[0.001]}\end{array}$ \\
\hline State Fixed Effects & Yes & Yes & Yes & Yes & Yes & Yes \\
\hline
\end{tabular}


Table 5: Evolution in Estimated Market Belief Parameters $(\pi), 1987-2007$

\begin{tabular}{|c|c|c|c|c|}
\hline \multirow[b]{2}{*}{ Market belief parameter $(\pi)$} & \multicolumn{2}{|c|}{ Beliefs based on Hadley $3 \mathrm{A2}$} & \multicolumn{2}{|c|}{ Beliefs based on CCSM 3 A2 } \\
\hline & (1a) & (1b) & (2a) & $(2 b)$ \\
\hline 1987 & $0.25 *$ & $(0.10)$ & $0.29 * *$ & $(0.10)$ \\
\hline 1992 & $0.24^{*}$ & $(0.09)$ & $0.28^{* * *}$ & $(0.08)$ \\
\hline 1997 & $0.27^{*}$ & $(0.10)$ & $0.28^{* * *}$ & $(0.08)$ \\
\hline 2002 & $0.17^{*}$ & $(0.08)$ & 0.09 & $(0.07)$ \\
\hline 2007 & 0.02 & $(0.09)$ & 0.00 & --- \\
\hline $\begin{array}{l}\text { F-statistic testing parameter equality } \\
\qquad[p \text {-value }]\end{array}$ & $\begin{array}{c}3.89 \\
{[0.010]}\end{array}$ & & $\begin{array}{c}4.13 \\
{[0.007]}\end{array}$ & \\
\hline
\end{tabular}

Notes: The estimated market belief parameters are from a pooled regression for 1987-2007 data that includes year and state fixed effects and quadratics in eight constructed future climate expectation index (equation 18). Standard errors are clustered on state. Asterisks denote $p$-value $<0.05\left({ }^{*}\right),<0.01\left({ }^{* *}\right),<0.001\left({ }^{* * *}\right)$. See the text for more details on the other control variables included in the regressions. 